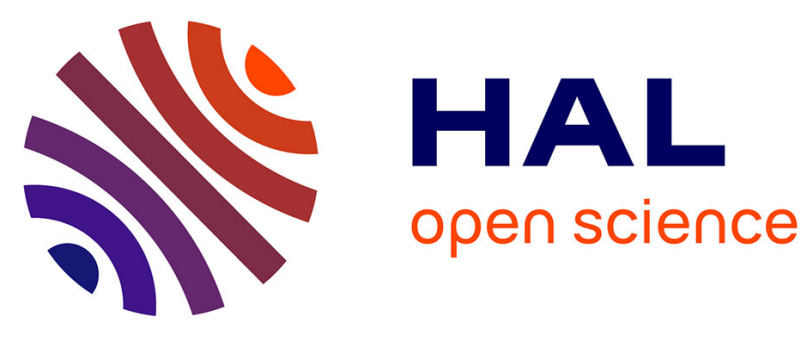

\title{
Contributions of Clouds, Surface Albedos, and Mixed-Phase Ice Nucleation Schemes to Arctic Radiation Biases in CAM5
}

Jason M. English, Jennifer E. Kay, Andrew Gettelman, Xiaohong Liu, Yong Wang, Yuying Zhang, Helene Chepfer

\section{To cite this version:}

Jason M. English, Jennifer E. Kay, Andrew Gettelman, Xiaohong Liu, Yong Wang, et al.. Contributions of Clouds, Surface Albedos, and Mixed-Phase Ice Nucleation Schemes to Arctic Radiation Biases in CAM5. Journal of Climate, 2014, 27 (13), pp.5174-5197. 10.1175/jcli-d-13-00608.1 . hal-01083048

\section{HAL Id: hal-01083048}

https: / hal-polytechnique.archives-ouvertes.fr/hal-01083048

Submitted on 12 Nov 2021

HAL is a multi-disciplinary open access archive for the deposit and dissemination of scientific research documents, whether they are published or not. The documents may come from teaching and research institutions in France or abroad, or from public or private research centers.
L'archive ouverte pluridisciplinaire HAL, est destinée au dépôt et à la diffusion de documents scientifiques de niveau recherche, publiés ou non, émanant des établissements d'enseignement et de recherche français ou étrangers, des laboratoires publics ou privés.

\section{(c)(1)}

Distributed under a Creative Commons Attribution| 4.0 International License 


\title{
Contributions of Clouds, Surface Albedos, and Mixed-Phase Ice Nucleation Schemes to Arctic Radiation Biases in CAM5
}

\author{
Jason M. English, ${ }^{*}$ Jennifer E. KAy, ${ }^{+}$Andrew Gettelman, ${ }^{\#}$ XiAOHOng LiU, ${ }^{@}$ \\ YONG WANG, ${ }^{\&}$ YUYing ZHANG, ${ }^{* *}$ AND HELENE CHEPFER $^{++}$ \\ * Laboratory for Atmospheric and Space Physics, University of Colorado Boulder, Boulder, Colorado \\ ${ }^{+}$Department of Atmospheric and Oceanic Sciences, University of Colorado Boulder, Boulder, Colorado \\ ${ }^{\#}$ Earth System Laboratory, National Center for Atmospheric Research, ${ }^{\# \#}$ Boulder, Colorado \\ ${ }^{\circledR}$ Department of Atmospheric Science, University of Wyoming, Laramie, Wyoming \\ ${ }^{\&}$ Department of Atmospheric Science, University of Wyoming, Laramie, Wyoming, \\ and Institute of Atmospheric Physics, Chinese Academy of Sciences, Beijing, China \\ ** Lawrence Livermore National Laboratory, Livermore, California \\ ${ }^{++}$LMD/IPSL, Université Pierre et Marie Curie, Paris, France
}

(Manuscript received 4 October 2013, in final form 7 March 2014)

\begin{abstract}
The Arctic radiation balance is strongly affected by clouds and surface albedo. Prior work has identified Arctic cloud liquid water path (LWP) and surface radiative flux biases in the Community Atmosphere Model, version 5 (CAM5), and reductions to these biases with improved mixed-phase ice nucleation schemes. Here, CAM5 net top-of-atmosphere (TOA) Arctic radiative flux biases are quantified along with the contributions of clouds, surface albedos, and new mixed-phase ice nucleation schemes to these biases. CAM5 net TOA allsky shortwave (SW) and outgoing longwave radiation (OLR) fluxes are generally within $10 \mathrm{~W} \mathrm{~m}^{-2}$ of Clouds and the Earth's Radiant Energy System Energy Balanced and Filled (CERES-EBAF) observations. However, CAM5 has compensating SW errors: Surface albedos over snow are too high while cloud amount and LWP are too low. Use of a new CAM5 Cloud-Aerosol Lidar and Infrared Pathfinder Satellite Observations (CALIPSO) lidar simulator that corrects an error in the treatment of snow crystal size confirms insufficient cloud amount in CAM5 year-round. CAM5 OLR is too low because of low surface temperature in winter, excessive atmospheric water vapor in summer, and excessive cloud heights year-round. Simulations with two new mixed-phase ice nucleation schemes - one based on an empirical fit to ice nuclei observations and one based on classical nucleation theory with prognostic ice nuclei-improve surface climate in winter by increasing cloud amount and LWP. However, net TOA and surface radiation biases remain because of increases in midlevel clouds and a persistent deficit in cloud LWP. These findings highlight challenges with evaluating and modeling Arctic cloud, radiation, and climate processes.
\end{abstract}

\section{Introduction}

Arctic near-surface air temperatures have warmed faster than the global average over the late twentieth and early twenty-first centuries. This "Arctic amplification" has been attributed to numerous possible processes and feedbacks, particularly sea ice loss (Serreze et al. 2009).

\footnotetext{
\#\# The National Center for Atmospheric Research is sponsored by the National Science Foundation.

Corresponding author address: Jason M. English, Laboratory for Atmospheric and Space Physics, University of Colorado Boulder, 3665 Discovery Drive, 600 UCB, Boulder, CO 80303.

E-mail: jayenglish@gmail.com
}

Modeling this observed Arctic climate change and projecting future Arctic climate change with general circulation models (GCMs) is challenging because of numerous complex processes and feedbacks. For example, small changes in surface type such as accumulating or melting snow and sea ice or changes in cloud amount, phase, or thickness can have large impacts on radiative fluxes. Hence, in order to accurately represent Arctic climate, models must accurately represent numerous components including surface type, cloud amount, and cloud phase. Indeed, climate models continue to disagree with representation of cloud cover in the current Arctic climate (Cesana and Chepfer 2012) and projection of surface warming and sea ice loss in the future (Karlsson and Svensson 2013; Liu et al. 2013). 
Over the past few decades, much new data have been gathered in the Arctic that can be used to improve process-level understanding and for climate model evaluation. Ground-based observational efforts such as the Surface Heat Budget of the Arctic Ocean (SHEBA) experiment in 1997-98 (Uttal et al. 2002), the U.S. Department of Energy (DOE) Mixed-Phase Arctic Cloud Experiment (M-PACE) in 2004 (Verlinde et al. 2007), and DOE Atmospheric Radiation Measurement Program (ARM) surface station measurements at the North Slope of Alaska (NSA) site in Barrow (Dong et al. 2010) are particularly useful for improving process understanding of Arctic clouds. Observations from these efforts have shown that mixed-phase clouds, which contain liquid water drops and ice crystals, are common in the Arctic, despite subfreezing temperatures (de Boer et al. 2009, 2011). The ubiquitous basinwide presence of liquid-containing clouds has also been detected using satellite observations (Cesana et al. 2012). The frequent occurrence of supercooled water is surprising given the Wegener-Bergeron-Findeisen (WBF) process (Wegener 1911; Bergeron 1935; Findeisen 1938), meaning ice crystals grow at the expense of liquid drops at subzero temperatures. Yet, many radiative, microphysical, dynamical, and surface processes govern the evolution and persistence of mixed-phase clouds [see, e.g., a recent review paper by Morrison et al. (2012)]. Comparisons of cloud frequency and liquid water path (LWP) to observations suggest that models generally underpredict the occurrence of mixed-phase Arctic clouds, leading to biases with surface radiative fluxes, and that simulated mixed-phase clouds are strongly sensitive to ice crystal number concentration (Morrison and Pinto 2006; Prenni et al. 2007; Xie et al. 2008; Klein et al. 2009; Xie et al. 2013). Despite having new double-moment microphysics, modeling studies with the latest version of the National Center for Atmospheric Research (NCAR) Community Atmosphere Model, version 5 (CAM5) (Neale et al. 2010) have suggested that CAM5 has smaller LWP and net surface radiation than M-PACE (Liu et al. 2011; Xie et al. 2008) and SHEBA (Morrison et al. 2012). The radiation biases in turn produce excessively strong temperature inversions and excessively cold winter temperatures in CAM5 (Medeiros et al. 2011; Pithan et al. 2014; de Boer et al. 2013). Due in part to smaller LWP and cloud amount, CAM5 is unable to reproduce the bimodal distribution of net surface longwave radiation observed during SHEBA in winter (Stramler et al. 2011; Morrison et al. 2012; Cesana et al. 2012). Sensitivity studies with new mixed-phase ice nucleation schemes in CAM5 have demonstrated improvements in LWP and surface radiative fluxes in the same region and time frame observed by M-PACE (Liu et al. 2011; Xie et al. 2008).
While field campaigns such as SHEBA and M-PACE have provided insights in particular regions, new satellite observations providing multiyear data across the entire Arctic basin are also proving useful for climate model evaluation (Kay et al. 2011; Cesana et al. 2012; Barton et al. 2012; Cesana and Chepfer 2012). Arctic basinwide top-of-atmosphere (TOA) radiative fluxes are available from the latest version of the Clouds and the Earth's Radiant Energy System (CERES; Wielicki et al. 1996) Energy Balanced and Filled (EBAF) data product (Loeb et al. 2009). Comparison of all-sky net TOA shortwave (SW) radiation and outgoing longwave (LW) radiation (OLR) between CAM5 and CERESEBAF can identify overall energy balance biases in the model. In addition, comparisons of clear-sky and cloudforcing radiative fluxes can help identify the contributions of cloud and surface albedo biases to all-sky biases. The contribution of cloud amount biases to cloudforcing biases can be studied by comparing modeled and observed cloud amount. Recent studies have emphasized the utility of active remote sensing for observing Arctic cloud amount. For example, the CloudAerosol Lidar and Infrared Pathfinder Satellite Observation (CALIPSO)-GCM-Oriented CALIPSO Cloud Product (CALIPSO-GOCCP) (Chepfer et al. 2010), which is a part of the A-Train (L'Ecuyer and Jiang 2010), is particularly useful (Cesana et al. 2012; Kay et al. 2012; Barton et al. 2012). Because of differences between modeled clouds and clouds observed by instruments, simulator packages such as the Cloud Feedback Model Intercomparison Project (CFMIP) (Bony et al. 2011) Observation Simulator Package (COSP) (BodasSalcedo et al. 2011), including a lidar simulator (Chepfer et al. 2008), are now commonly utilized to enable a more direct comparison of modeled clouds to observations. Assumptions are often made in the parameterizations that apply the simulator algorithms to model output, however, and there continues to be opportunities to improve the accuracy of using instrument simulators on model output. The CAM5 lidar simulator, which has been built on the COSP lidar (Chepfer et al. 2008), has recently included the effects of atmospheric snow crystals in the lidar simulator (Barton et al. 2012; Kay et al. 2012). Recent work has utilized these new tools to investigate the impacts of new CAM5 mixed-phase ice nucleation schemes on clouds and radiation and identified changes to cloud amount and cloud properties (Xie et al. 2013). There are several opportunities to expand upon this work, including conducting an analysis of the contributions of clouds and surface albedo to net TOA radiation biases in CAM5, comparing year-round (rather than March-September) net TOA radiation biases to CERES-EBAF version 2.7 
(rather than version 2.6), and evaluating cloud amount from a lidar simulator that contains a correction for an error in the treatment of snow crystal size.

The primary goals of this paper are to quantify CAM5 Arctic basinwide net TOA radiation biases and to determine the contributions of clouds, surface albedos, and mixed-phase ice nucleation schemes to these biases. We utilize CERES-EBAF all-sky, clear-sky, and cloudforcing fluxes to identify TOA radiative biases and the relative contributions of surface albedo and clouds. We utilize CALIPSO-GOCCP cloud amount (Chepfer et al. $2010,2013)$ together with a CALIPSO lidar simulator to identify spatial biases in modeled cloud amount. The present work investigates a correction for an error in the treatment of snow crystal size in the lidar simulator (section 3). Finally, we examine the impacts of new mixed-phase ice nucleation schemes on net TOA radiative fluxes, cloud amount, and Arctic weather states as determined by the frequency distribution of net surface longwave radiation. The paper is organized as follows: Section 2 describes methods for models, datasets, and analysis. In section 3, we discuss CAM5 cloud amount using the CALIPSO simulator including the impacts of a correction for an error in the treatment of snow crystal size. In section 4, CAM5 net TOA radiative flux biases are quantified along with contributions from clouds and surface albedos. Section 5 presents the impacts of two modified mixed-phase ice nucleation schemes on Arctic clouds, radiation, and distribution of weather states. Section 6 provides further discussion and conclusions.

\section{Methods}

\section{a. CAM5 model description}

We use CAM5 (version 5.1.05) released with Community Earth System Model, version 1.0.4 (CESM1) (Hurrell et al. 2013), and is the model version utilized as part of phase 5 of the Coupled Model Intercomparison Project (CMIP5). CAM5, which is the atmospheric component of CESM1, includes a double-moment cloud microphysics scheme that predicts prognostic mass and number mixing ratio of cloud liquid and ice based on many microphysical processes including hydrometeor collection, condensation/evaporation, freezing, melting, sedimentation, and activation of droplets on aerosol (Morrison and Gettelman 2008). The WBF process is included, which allows conversion of cloud liquid to cloud ice because of lower equilibrium vapor pressure over ice than liquid. Ice nucleation, vapor deposition on ice crystals, and ice supersaturation are also included (Gettelman et al. 2010). Although CAM5 introduces numerous improvements in cloud microphysics compared to CAM4, mixed-phase ice nucleation remains parameterized based
TABLE 1. Summary of the mixed-phase ice nucleation schemes evaluated in CAM5.

\begin{tabular}{ccc}
\hline Scheme & \multicolumn{1}{c}{ Representation } & Notes \\
\hline CAM5 Meyers & $\begin{array}{c}\text { Empirical fit to Meyers et al. } \\
\text { (1992). }\end{array}$ & $\begin{array}{c}\text { CAM5 default } \\
\text { scheme }\end{array}$ \\
CAM5 Prenni & $\begin{array}{c}\text { Empirical fit to Prenni et al. } \\
\text { (2007). }\end{array}$ & - \\
CAM5 Hoose & $\begin{array}{l}\text { Physical representation based } \\
\text { on laboratory measurements } \\
\text { and classical nucleation theory } \\
\text { (Hoose et al. 2010). }\end{array}$ \\
\hline
\end{tabular}

on Meyers et al. (1992), which has too many Arctic ice nuclei when compared to observations (Prenni et al. 2007; DeMott et al. 2010). The model also includes moist turbulence (Bretherton and Park 2009), shallow convection (Park and Bretherton 2009), diagnostic cloud amount, and a new radiation scheme (Iacono et al. 2008). Aerosols are represented in three modes (Aitken, accumulation, and coarse) using a new modal aerosol module (Liu et al. 2012). The model has 30 vertical levels, with 10 levels between the surface and $3 \mathrm{~km}$. We run the standard 30-min physics time steps with two substeps for the cloud microphysics code. The land model component of CAM5, which is the same as the Community Climate System Model, version 4 (CCSM4), has a detailed snow model (Lawrence et al. 2011) that includes the effects of aerosol deposition (e.g., black and organic carbon and dust) on albedo; introduces a grain-size-dependent snow aging parameterization; and permits vertically resolved snowpack heating (Flanner and Zender 2005, 2006; Flanner et al. 2007), a density-dependent snowcover fraction parameterization (Niu and Yang 2007), a revised snow burial fraction over short vegetation (Wang and Zeng 2009), and corrections to snow compaction (Lawrence and Slater 2010).

\section{b. CAM5 simulations}

Three 11-yr (2000-10) CAM5 simulations are completed at $0.95^{\circ} \times 1.25^{\circ}$ horizontal resolution: a CMIP5 reference case ("CAM5 Meyers") and two simulations with modified mixed-phase ice nucleation schemes ("CAM5 Prenni" and "CAM5 Hoose") (Table 1). All three simulations are run with prescribed sea ice extent and sea surface temperature (SST). The three simulations are named for their treatment of ice nuclei concentration and are further described below.

CAM5 Meyers uses the default CMIP5 CAM5 model physics. CAM5 has empirical parameterizations for cloud microphysical processes in the mixed-phase regime (temperatures between $0^{\circ}$ and $-37^{\circ} \mathrm{C}$ ), which include immersion freezing (Bigg 1953), contact nucleation (Young 
1974), and deposition/condensation freezing (Meyers et al. 1992). Deposition/condensation freezing is responsible for more than $90 \%$ of the ice nuclei formed in CAM5 mixed-phase clouds. This simulation is named for Meyers et al. (1992), who derived a formula for the number of activated ice nuclei from vapor deposition/ condensation freezing that is a function of ice supersaturation partially fitted to aircraft observations of ice crystal number as a function of temperature over Wyoming (Fletcher 1962).

CAM5 Prenni uses the same parameterizations for immersion freezing and contact nucleation, but replaces the coefficients in the deposition/condensation freezing formula of Meyers et al. (1992) with those fitted to observations during the M-PACE (Prenni et al. 2007). During M-PACE, concentrations of ice nuclei were approximately an order of magnitude lower than the formula derived by Meyers et al. (1992). The discrepancy may be due to the differences in location, as other studies have observed lower ice nuclei concentrations in the Arctic (e.g., Bigg 1996) than Meyers et al. (1992) observed over Wyoming.

CAM5 Hoose replaces the empirical parameterizations for immersion freezing, contact nucleation, and vapor deposition/condensation freezing with a physical representation of these processes based upon laboratory measurements and classical nucleation theory (Hoose et al. 2010). The mixed-phase nucleation rates are determined by the number, size distribution, and surface properties of mineral dust and black carbon in the interstitial and cloud-borne phases (Wang et al. 2014). The aerosol number and size distribution are calculated from the aerosol module in CAM5 (Liu et al. 2012), and the aerosol surface properties are derived by fitting to respective laboratory data of mineral dust and black carbon (Hoose et al. 2010).

\section{c. TOA radiative fluxes (CERES-EBAF 2.7)}

CERES-EBAF is the only available source of basinwide TOA fluxes in the Arctic, and newer versions have advanced to distinguish clouds from underlying highalbedo sea ice and snow cover by utilizing cloud radiances from the collocated Moderate Resolution Imaging Spectroradiometer (MODIS) and sea ice concentration fields from the National Snow and Ice Data Center (NSIDC) (Hollinger et al. 1990). We analyze $11 \mathrm{yr}$ of data (2000-10) from CERES-EBAF version 2.7, released in June 2013, which further improves calculation of clear-sky fluxes by including CERES partly cloudy data points in the calculation. CERES-EBAF all-sky error is estimated to be $5-10 \mathrm{~W} \mathrm{~m}^{-2}$ (Loeb et al. 2007). We quantify the contributions of clouds and surface albedos to all-sky biases by comparing model output to
CERES-EBAF clear-sky and cloud-forcing biases. However, there remain significant uncertainties with retrievals of clear-sky and cloud-forcing fluxes at high latitudes because of difficulty distinguishing clouds from snow, and it is difficult to quantify these uncertainties. A recent study suggested that errors in CERES-EBAF cloud detection caused errors in cloud forcing of up to 8.5\% (Liu et al. 2010).

\section{d. Cloud amount (CALIPSO-GOCCP)}

We use CALIPSO-GOCCP lidar observations (Chepfer et al. 2010) to assess cloud amount and vertical structure. CALIPSO-GOCCP is well suited for Arctic assessments and has been utilized in other model-observation comparisons (Kay et al. 2012; Barton et al. 2012). CALIPSO-GOCCP cloud detection is unaffected by the surface conditions or thermal structure of the atmosphere and is therefore more reliable than passive remote sensing in the Arctic. CALIPSO-GOCCP is able to detect near-surface clouds in the boundary layer as well as optically thin clouds, which are both common in polar regions. CALIPSO-GOCCP cannot detect clouds with a scattering ratio of less than 5 (roughly equivalent to a cirrus cloud with an optical depth of less than 0.1 ) (Chepfer et al. 2013) and cannot see the entire vertical extent of clouds if the optical depth is greater than 5 (Winker et al. 2009). We compare CAM5 model output to CALIPSO-GOCCP observations by utilizing the COSP CALIPSO lidar simulator that includes a correction for an error in the treatment of snow crystal size. This improved treatment of atmospheric snow crystals causes significant differences in the CALIPSO lidar simulated cloud amount. A more detailed description of the COSP CALIPSO lidar simulator and comparison of output with and without the correction are covered in section 3 .

\section{e. Domain of the Arctic}

For our Arctic basinwide comparisons, we define the Arctic as the region between $60^{\circ}$ and $82^{\circ} \mathrm{N}$. This includes polar continental landmasses (most of Alaska and Greenland and the northern half of Canada and Siberia) as well as most of the Arctic Ocean. We exclude the region north of $82^{\circ} \mathrm{N}$ to provide a fair comparison between model output and observations as CALIPSOGOCCP extends to $82^{\circ} \mathrm{N}$. Restricting the latitude range in this manner did not significantly affect conclusions, consistent with previous studies of latitude ranges in the Arctic with CERES-EBAF (Kay and L'Ecuyer 2013) and CALIPSO-GOCCP cloud amount (Kay et al. 2012). Hence, for consistency between radiative flux and cloud comparisons we conduct the majority of our analyses across the region $60^{\circ}-82^{\circ} \mathrm{N}$. The model is evaluated in 
three regions: the entire Arctic basin, land, and water. Model grid boxes with land fraction less than 0.5 are designed as water; otherwise, they are designated as land. The water designation includes sea ice as well as open ocean. We average years 2000-10 when comparing to CERES-EBAF and years 2006-10 when comparing to CALIPSO-GOCCP. While sea ice cover is not the same when averaging 2000-10 versus 2006-10, analysis of polar spatial plots can ensure this difference is not convoluting analysis. Observational data are regridded to the CAM5 $0.9^{\circ}$ by $1.25^{\circ}$ horizontal grid using piecewise linear interpolation and the same surface mask is applied for comparison.

\section{Updates to the CAM5 CALIPSO lidar simulator}

In this section, we describe the new CAM5 lidar simulator with a correction for an error in the treatment of snow crystal size and the impacts the new version has on simulated cloud amount and cloud structure. Later, we evaluate CAM5 net TOA radiative flux biases compared to CERES-EBAF and determine contributions from clouds biases and surface albedo biases.

\section{a. Description}

To compare CAM5 model output of cloud amount to $C A L I P S O$-GOCCP observations, we use the COSP CALIPSO lidar simulator (Chiriaco et al. 2006; Chepfer et al. 2007). The standard version of the COSP CALIPSO lidar simulator released for CMIP5 includes the impacts of clouds only (Chepfer et al. 2008). The more recent CAM5 version of the lidar simulator also includes the impacts of radiatively active snow crystals on the simulated lidar signal (Kay et al. 2012) and is referred to here as the CAM5 CMIP5 version of the lidar simulator. In the CAM5 CMIP5 lidar simulator, the maximum particle radius was set to $70 \mu \mathrm{m}$ for both cloud ice and snow. While this maximum is valid for computing the backscatter to extinction ratio since the latter is constant as soon as the particle is larger than the wavelength $(0.532 \mu \mathrm{m}$ for $C A L I P S O)$, this maximum is not valid to compute the extinction coefficient as a function of the actual particle size. To address this issue for snow, in the current work the particle size determined by model simulated snow crystals is used to calculate the extinction coefficient. This can significantly affect the observable cloud amount, as for a fixed water mass allowing for larger particle sizes would lead to smaller total extinction and eventually to less cloud fraction.

\section{b. Arctic cloud amount}

When comparing 2006-10 average cloud amount to the CAM5 CMIP5 lidar simulator (Kay et al. 2012), the new CAM5 lidar simulator has lower cloud amount year-round, particularly in winter months (Fig. 1). The reduced cloud amount (relative to CAM5 CMIP5) results from increased snow crystal size. A larger snow crystal size increases the extinction coefficient and decreases the calculated attenuation coefficient, leading to a smaller lidar backscatter. Across the Arctic basin, total, high, middle, and low simulated cloud amount is lower in CAM5 with the new lidar simulator than CALIPSO-GOCCP observations year-round. Spatially, CAM5 annual average cloud amount is too low over the Arctic Ocean and continental landmasses but agrees well with CALIPSO-GOCCP over the Greenland Sea, North Atlantic Ocean, and North Pacific Ocean (Fig. 2). Vertical contour plots of CAM5 seasonal cloud amount with the new lidar simulator compared to the CAM5 CMIP5 version (Fig. 3) reveal a significant reduction in cloud amount in middle and upper troposphere (from 3 to $9 \mathrm{~km}$ in winter months and from 6 to $12 \mathrm{~km}$ in summer months) as well as a reduction of low cloud in winter. Compared to CALIPSO-GOCCP observations, CAM5 with the new lidar simulator has insufficient cloud amount in the first few kilometers above Earth's surface most of the year, which would result in excessive radiative cooling and excessively cold winters in the model. Above about $5 \mathrm{~km}$, CAM 5 with the new lidar simulator has excessive cloud amount. Excessive middle and high cloud amount in CAM5 is also present when compared to vertical contour plots of cloud amount from the ARM NSA surface station in Barrow (not shown).

It is counterintuitive that based on vertical contour plots (Fig. 3) CAM5 has excessive middle and high clouds, yet plots of average high and middle cloud amount (Fig. 1) suggest that CAM5 has insufficient cloud amount. This perceived discrepancy is explained by considering that clouds have both a frequency of occurrence and a vertical extent. A bias in the frequency of cloud occurrence of high cloud would cause a bias in Fig. 1. A bias in the vertical extent of clouds at a given cloud frequency would cause a bias in Fig. 3. (The vertical extent of clouds in the model is set by the presence of prognostic condensate. For the radiation code, a maximum-random overlap assumption is used.) This possibility is explored further by comparing monthly average cloud amount to instantaneous output of the vertical profile of cloud amount at a single latitude and longitude (in this case, Barrow, Alaska). In spring, for example, CAM5 has insufficient total, high, middle, and low cloud compared to CALIPSO-GOCCP (Figs. 4a-d), yet CAM5 has excessive cloud amount between 5 and $9 \mathrm{~km}$ when plotting a vertical profile of cloud amount bias compared to CALIPSO-GOCCP (Fig. 4f). Plotting instantaneous output of cloud amount shows that 
Total cloud over basin

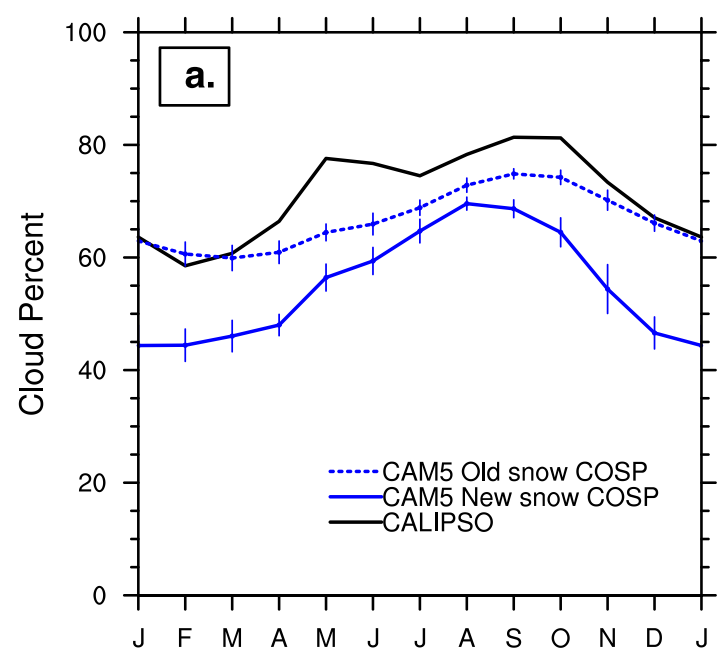

Mid cloud over basin

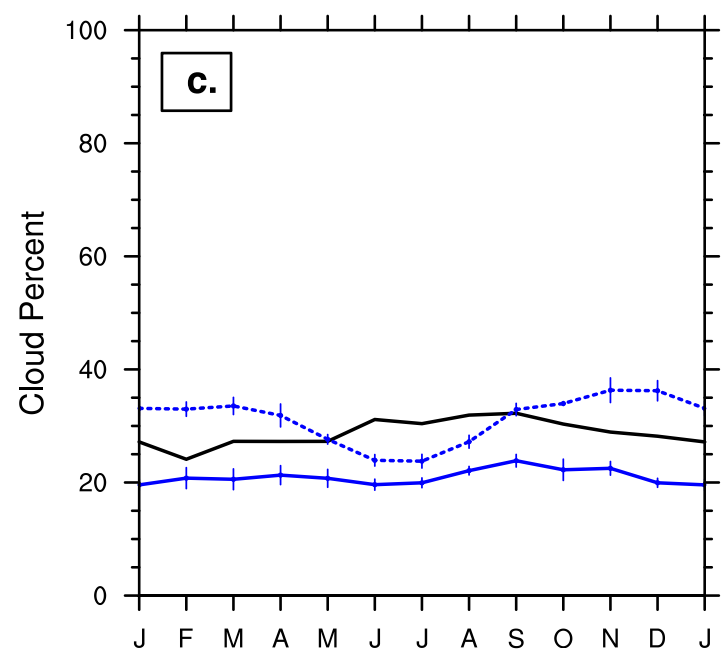

High cloud over basin

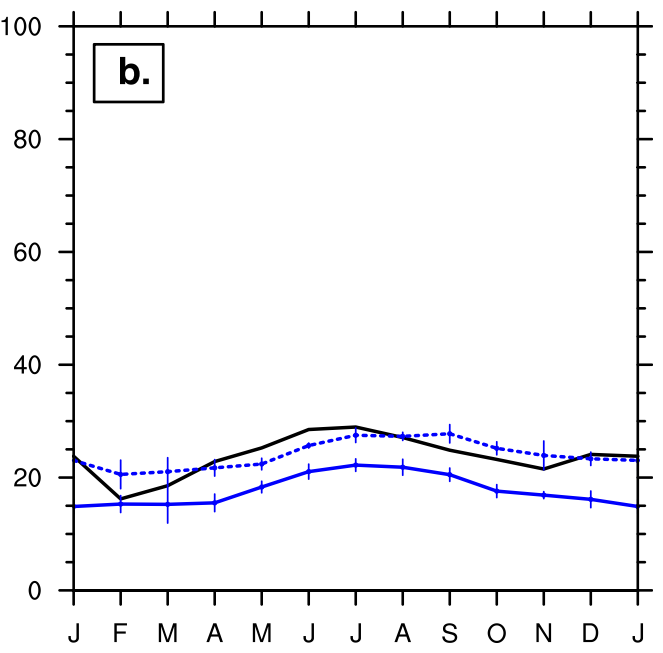

Low cloud over basin

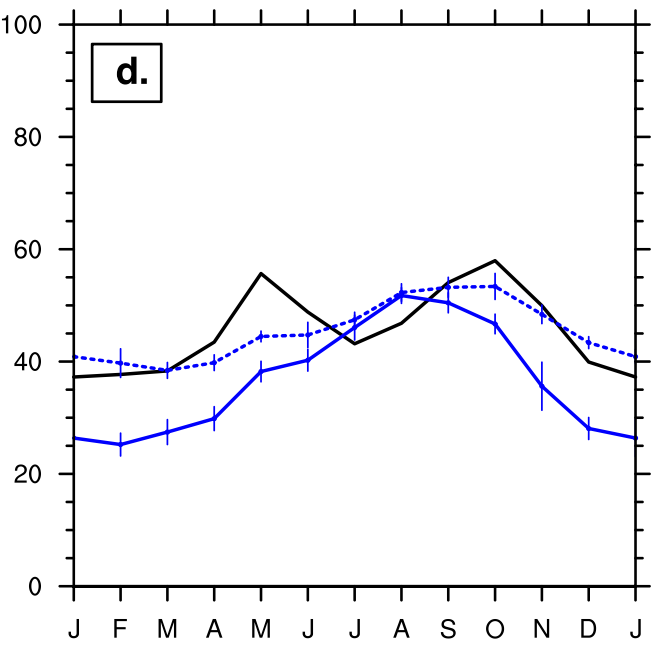

FIG. 1. Seasonal cycle of monthly average (a) total, (b) high, (c) middle, and (d) low cloud amount (\%) from $60^{\circ}$ to $82^{\circ} \mathrm{N}$ for 5-yr average (2006-10) of CALIPSO-GOCCP observations (black lines) and model simulations using the CALIPSO lidar simulator (blue lines). Dotted lines are for the CAM5 CMIP5 version of the lidar simulator (CAM5 old snow COSP); solid lines are for the new CAM5 lidar simulator with a correction for an error in the treatment of snow crystal size (CAM5 new snow COSP). Error bars represent standard deviation of monthly averages across the 5-yr time period.

CAM5 clouds are generally tall when they occur (Fig. 4e). In other words, cloud frequency of occurrence in CAM5 is about $5 \%$ too low but, when clouds do occur in the model, they span too much of the vertical column. The excessive cloud vertical extent is not limited to the Arctic; CAM5 average high and middle cloud amount between $60^{\circ} \mathrm{S}$ and $60^{\circ} \mathrm{N}$ is about $5 \%$ lower than CALIPSOGOCCP, while vertical contour plots in the same latitude range find CAM5 to have about $5 \%$ higher cloud amount than CALIPSO-GOCCP between 9 and $15 \mathrm{~km}$ (not shown). Other studies have identified low frequency of CAM5 cloud amount (Barton et al. 2012) and excessive CAM5 cloud amount in the middle and upper Arctic troposphere (Barton et al. 2012; Xie et al. 2013). Additionally, a comparison of our CAM5 simulation to cloud amount at the ARM NSA site in Barrow suggests excessive CAM5 clouds in the middle and upper troposphere (not shown). Another possibility for insufficient low cloud using the lidar simulator could be due to attenuation when the clouds above have an optical depth of greater than 5. However, CAM5 Arctic clouds are optically thin in the colder months; monthly average column-integrated optical depth is greater than 5 in only $5 \%$ of the Arctic grid boxes in winter. Above 

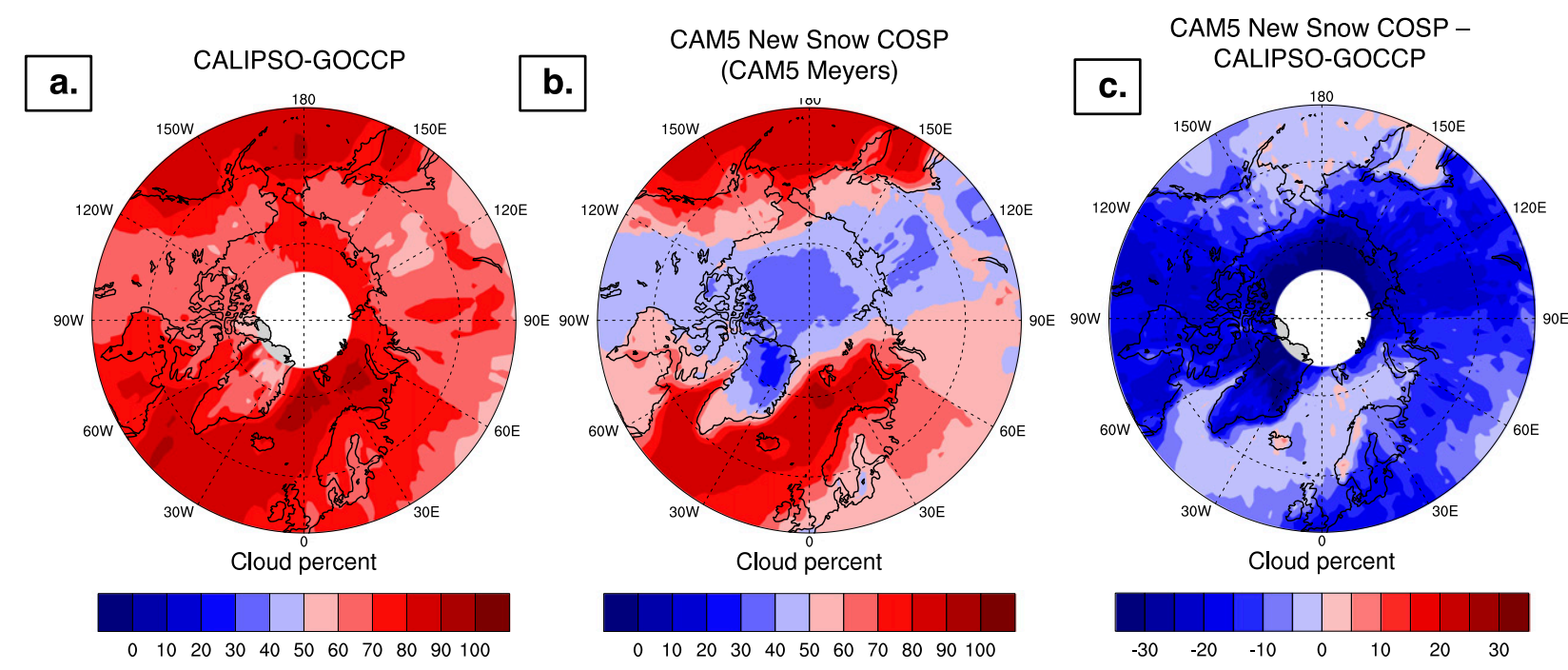

FIG. 2. Annual average polar spatial plots of cloud amount (\%) across a 5-yr time period (2006-10) for (a) CALIPSO-GOCCP observations, (b) the new CAM5 lidar simulator with a correction for an error in the treatment of snow crystal size (CAM5 new snow COSP), and (c) CAM5 minus CALIPSO-GOCCP.

$800 \mathrm{hPa}$, CAM5 optical depth is greater than 5 in less than $1 \%$ of Arctic grid boxes in winter. This suggests it is not instrument attenuation to blame; rather, the model has tall thin clouds and insufficient clouds/optically thin clouds below $3 \mathrm{~km}$. In the summer, however, above $800 \mathrm{hPa}, \mathrm{CAM} 5$ cloud optical depth is greater than 5 in about $30 \%$ of grid boxes, suggesting instrument attenuation may make a minor contribution to insufficient low cloud amount.

\section{Results: CAM5 Arctic TOA radiative fluxes}

With an assessment of cloud amount using the new CAM5 lidar simulator with a correction for an error in the treatment of snow crystal size complete, we next evaluate net TOA radiative fluxes in the model.

\section{a. Arctic net TOA SW radiative flux biases}

The seasonal cycles of CAM5 CMIP5 (CAM5 Meyers) net TOA SW radiative fluxes across the Arctic basin $\left(60^{\circ}-82^{\circ} \mathrm{N}\right)$ are compared to CERES-EBAF in Fig. 5. A 4-yr CESM1 simulation (2003-06), which is the fully coupled model version containing the CAM5 atmospheric component, is also evaluated for comparison to CAM5 Meyers (2000-10). For SW all sky, CAM5 and CESM1 are generally within $10 \mathrm{~W} \mathrm{~m}^{-2}$ of CERESEBAF year-round over all three surface types (basin, land, and water), except in late summer over water. The magnitudes of winter SW all-sky biases are smaller than in summer due in part to smaller incoming solar insolation in winter. When comparing net SW clear sky to CERESEBAF (Figs. 5d-f), CAM5 generally has negative biases most of the year, except in late summer over water. In contrast, CAM5 generally has positive SW cloud-forcing biases (Figs. 5g-i), meaning clouds let too much SW into the Arctic system, which is due to insufficient Arctic cloud amount in CAM5 (Fig. 1). Other biases are possible including cloud LWP, cloud droplet size, or cloud optics. The COSP CALIPSO simulator allows the user to specify spherical or nonspherical ice particle shape. We specify spherical shape, which is the default and also what is assumed in the CAM5 cloud optics code and the cloud microphysics code (i.e., fall speeds). This suggests that CAM5 has compensating biases between surface albedo and cloud forcing, which result in a lower bias when comparing TOA SW all sky. Assuming no significant atmospheric contributions to SW clear-sky radiative fluxes, clear-sky biases are assumed to be largely due to surface albedo biases. CAM5 and CESM1 monthly all-sky, clear-sky, and cloud-forcing biases have a similar seasonal cycle at both wavelengths, suggesting that the atmospheric component of CESM1 is driving most of the radiative flux biases, rather than feedbacks between the fully coupled ocean, sea ice, and land components. One notable exception is that CESM1 has a larger SW clear-sky bias over land during the late spring in early summer (Fig. 5e). This is attributed to higher snow cover over land in CESM1, suggesting that CESM1 snow cover may be too high.

CAM5 has a SW clear-sky bias over water that is too low by about $20 \mathrm{~W} \mathrm{~m}^{-2}$ in spring and early summer [April-June (AMJ)] and too high by about $20 \mathrm{~W} \mathrm{~m}^{-2}$ in late summer [July-September (JAS)] (Fig. 5f). The clear-sky bias in AMJ is compensated by an equally 

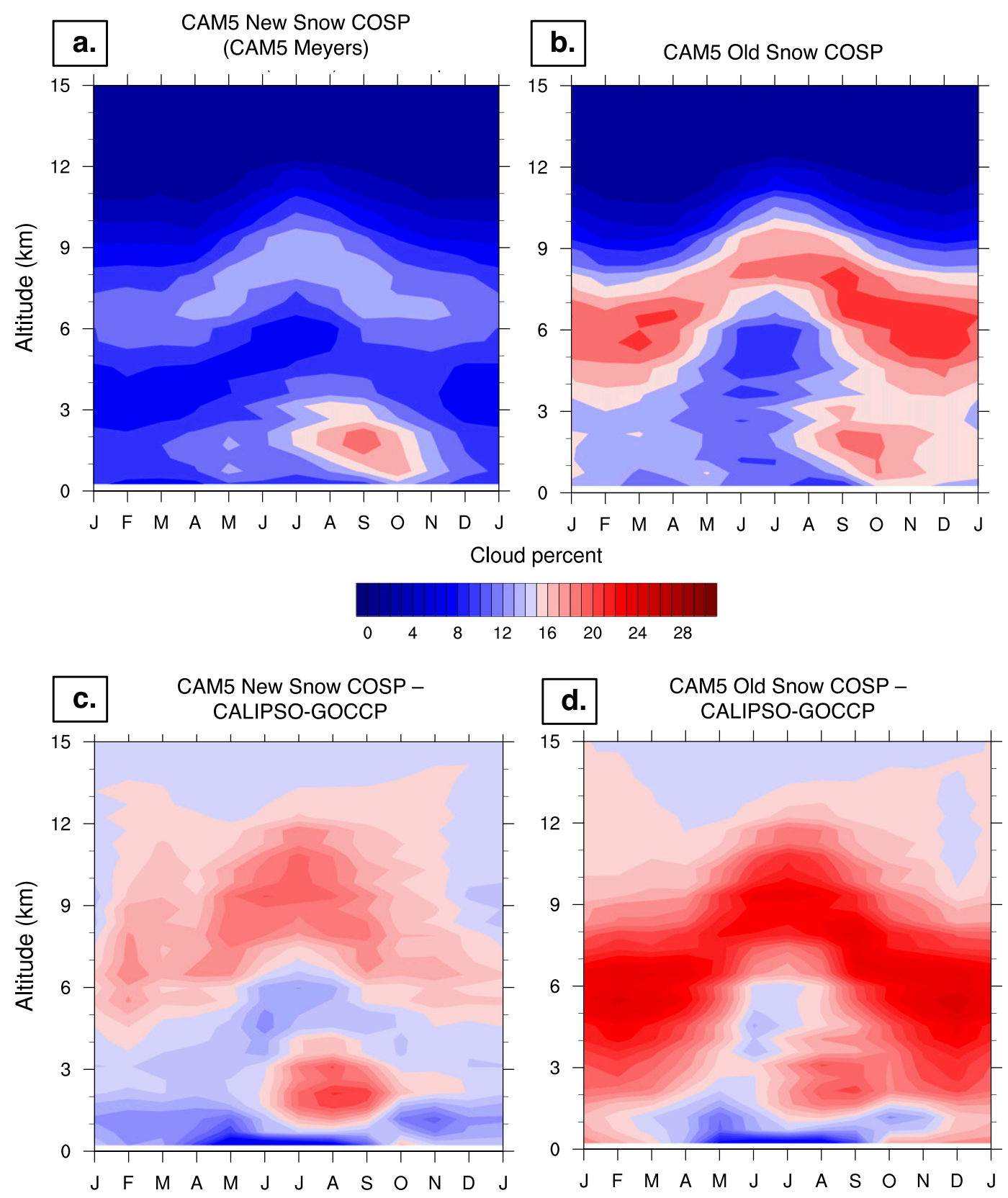

Cloud percent

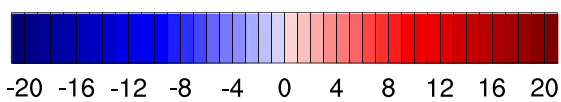

FIG. 3. Vertical contour plots of seasonal cycle of monthly average cloud amount (\%) from $60^{\circ}$ to $82^{\circ} \mathrm{N}$ for 5 -yr average (2006-10) of (a) the new CAM5 lidar simulator with a correction for an error in the treatment of snow crystal size (CAM new snow COSP) and (b) the CAM5 CMIP5 version of the lidar simulator (CAM5 old snow COSP) and (c),(d) difference plots from a 5-yr average (2006-10) of CALIPSO-GOCCP observations.

positive cloud-forcing bias (Fig. 5i) resulting in a nearzero all-sky bias (Fig. 5c). However, the clear-sky bias in JAS drives a corresponding all-sky bias as a result of a lack of compensation from cloud forcing. This clear-sky bias is further explored in polar spatial plots of SW allsky, clear-sky, and cloud-forcing biases during these two seasons (Fig. 6). While basinwide average TOA SW biases tend to be less than $10 \mathrm{~W} \mathrm{~m}^{-2}$, spatial biases in 
Total cloud over Barrow
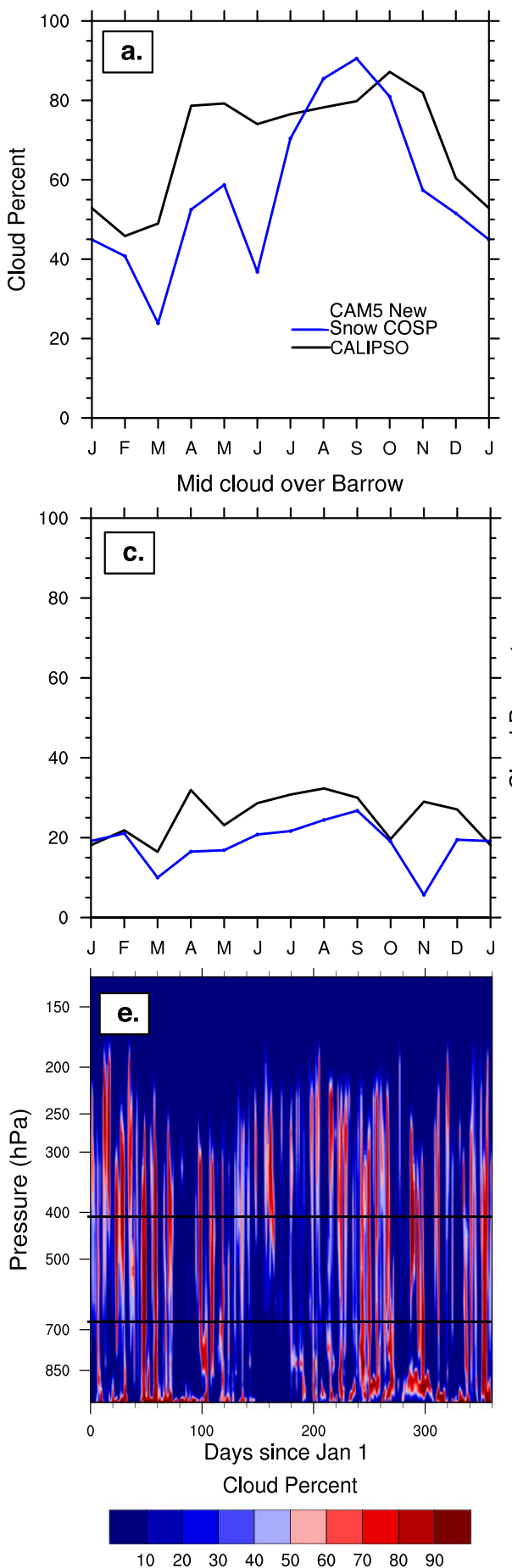

High cloud over Barrow
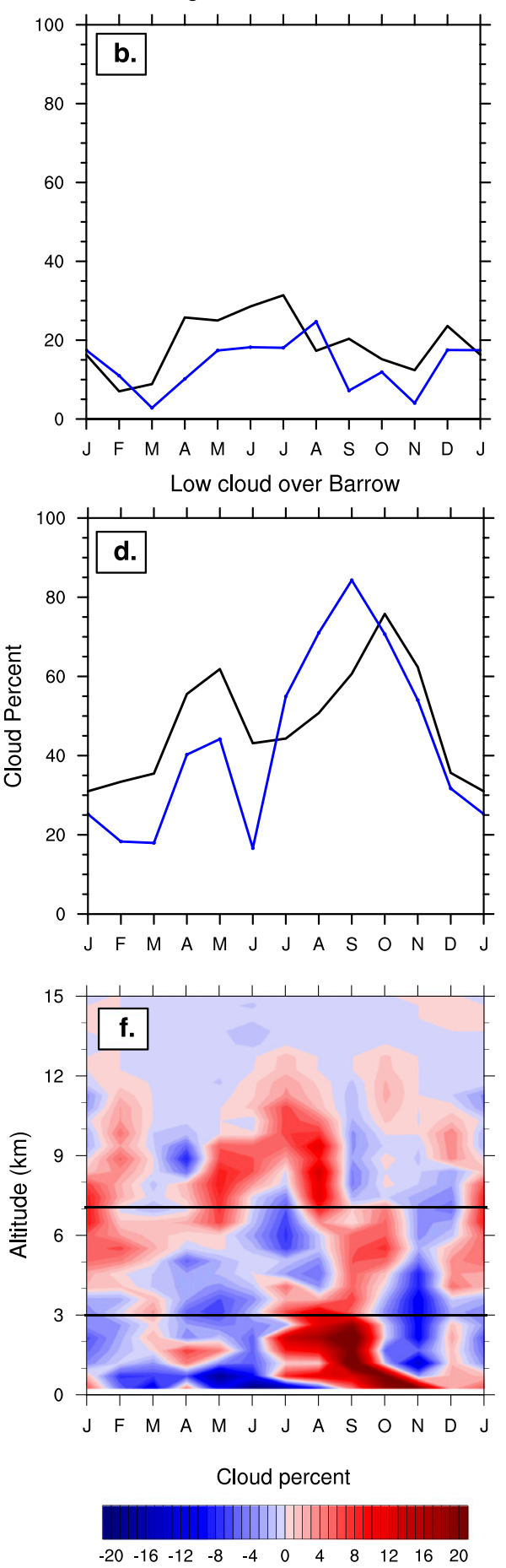

FIG. 4. Investigation of vertical profile of CAM5 cloud amount at Barrow, Alaska $\left(71^{\circ} \mathrm{N}, 157^{\circ} \mathrm{W}\right)$. (a)-(d) Seasonal cycle of monthly average total, high, middle, and low cloud amount for the new CAM5 lidar simulator with a correction for an error in the treatment of snow crystal size (CAM5 new snow COSP; blue lines) and CALIPSO-GOCCP observations (black lines). (e) Instantaneous output of native CAM5 cloud amount at 27-h intervals for the year 2005. Horizontal lines represent boundaries between high, middle, and low cloud. (f) Vertical contour plot of seasonal cycle of monthly average cloud amount bias (the new CAM5 lidar simulator with a correction for an error in the treatment of snow crystal size minus CALIPSO-GOCCP) for the year 2005. Horizontal lines represent boundaries between high, middle, and low cloud. 

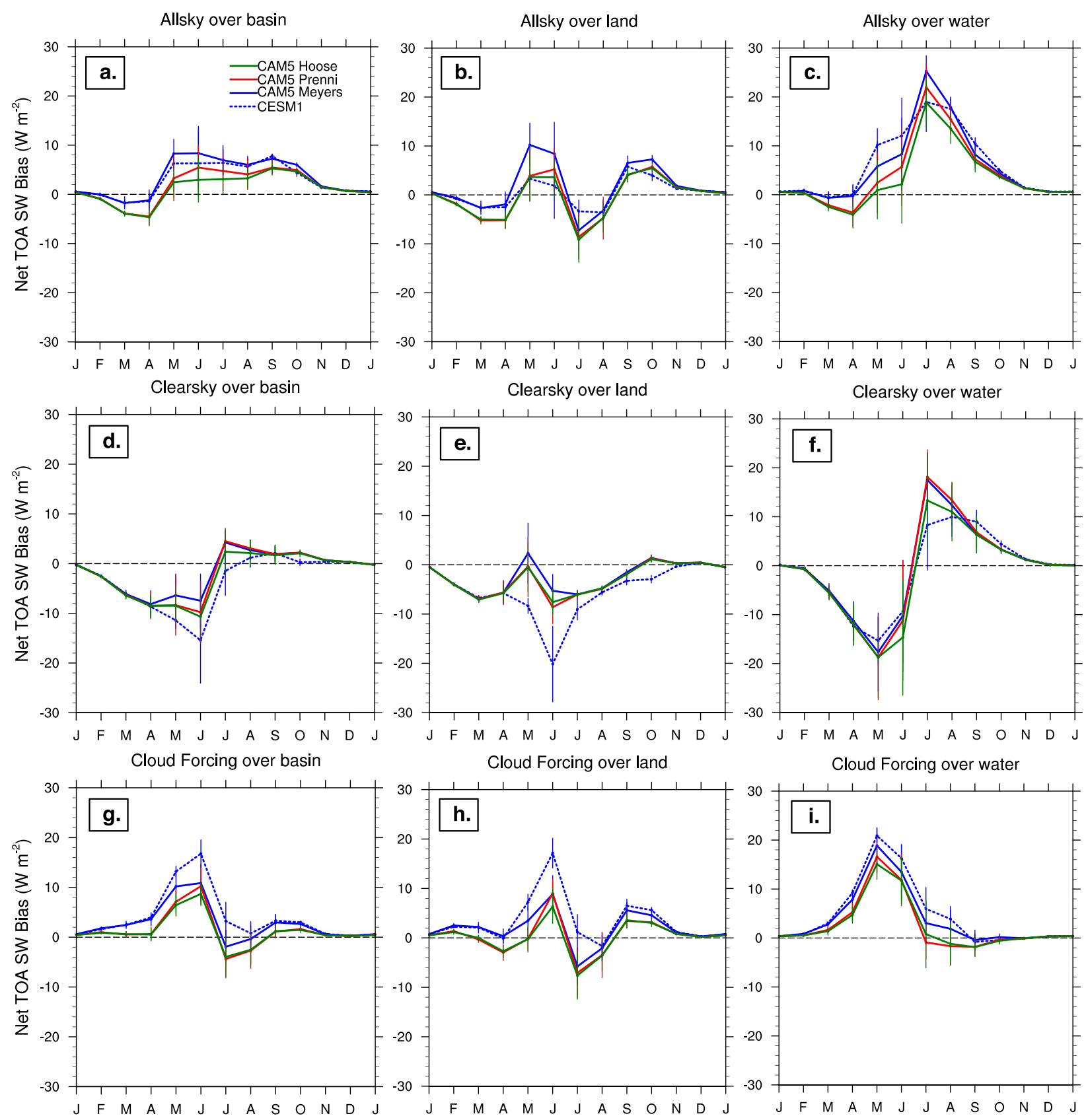

FIG. 5. Seasonal cycle of monthly average net TOA SW (a)-(c) all-sky, (d)-(f) clear-sky, and (g)-(i) cloud-forcing radiation biases in the Arctic $\left(60^{\circ}-82^{\circ} \mathrm{N}\right)$ for model simulations minus CERES-EBAF observations. CAM5 Meyers and CESM1 use the CMIP5 reference mixed-phase ice nucleation scheme (Meyers et al. 1992), CAM5 Prenni uses M-PACE observations (Prenni et al. 2007), and CAM5 Hoose uses classical nucleation theory (Hoose et al. 2010). CAM5 simulations are 11-yr averages (2000-10), CESM1 is a 4-yr average (2003-06), and CERES-EBAF observations are 11-yr averages (2000-10). Model grid boxes with land fraction less than 0.5 are designed as water; otherwise, they are designated as land. A positive net TOA SW bias means the model predicts excess SW fluxes entering the Arctic system.

each grid box across the Arctic basin of SW all-sky, clearsky, and cloud forcing range from -50 to $50 \mathrm{~W} \mathrm{~m}^{-2}$. In both AMJ and JAS over water, there is a clear pattern of SW all-sky, clear-sky, and cloud-forcing biases over the domain that corresponds to the coverage of the polar ice cap (Figs. 7a,b, respectively). As the CAM5 model simulations were run with prescribed sea ice extent and SST, it is unlikely that SW clear-sky biases 

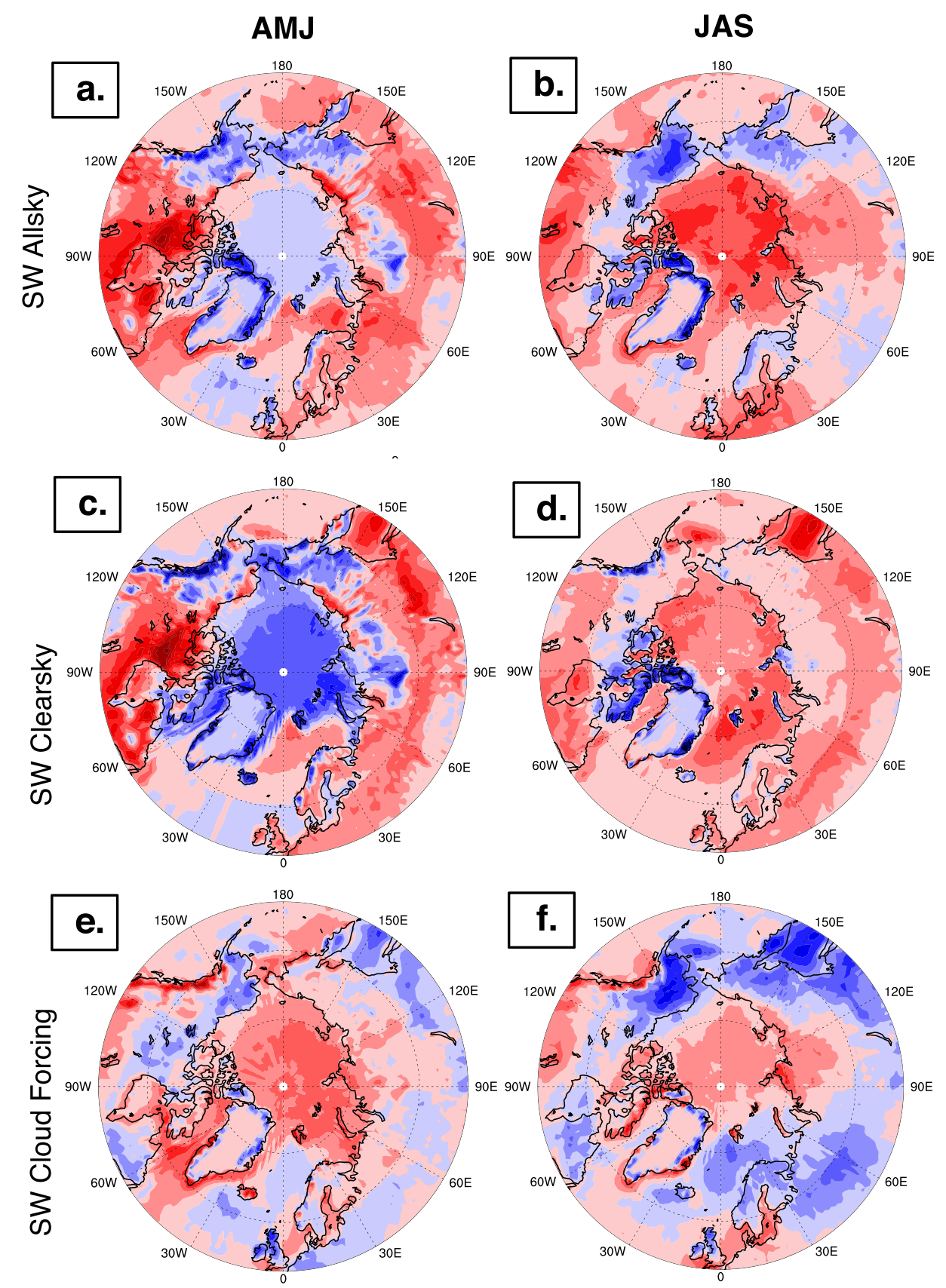

Net TOA SW Bias $\left(\mathrm{Wm}^{-2}\right)$

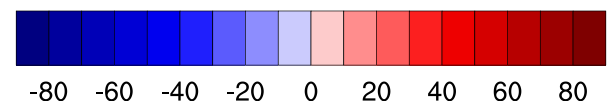

FIG. 6. AMJ and JAS polar spatial plots of net TOA SW (a),(b) all-sky, (c),(d) clear-sky, and (e),(f) cloud-forcing biases (CAM5 Meyers - CERES-EBAF) across 11 yr (2000-10).

are due to sea ice extent errors. The clear-sky bias over sea ice is about $30 \mathrm{~W} \mathrm{~m}^{-2}$ too low in AMJ and then becomes a little too high in JAS. This corresponds to snow being present on sea ice in AMJ and mostly melting by JAS (Figs. 7c,d, respectively), suggesting model albedo errors when snow is present on sea ice. In addition to SW clear-sky biases over sea ice, CAM5 SW clear sky is about $40 \mathrm{~W} \mathrm{~m}^{-2}$ too low over some land 

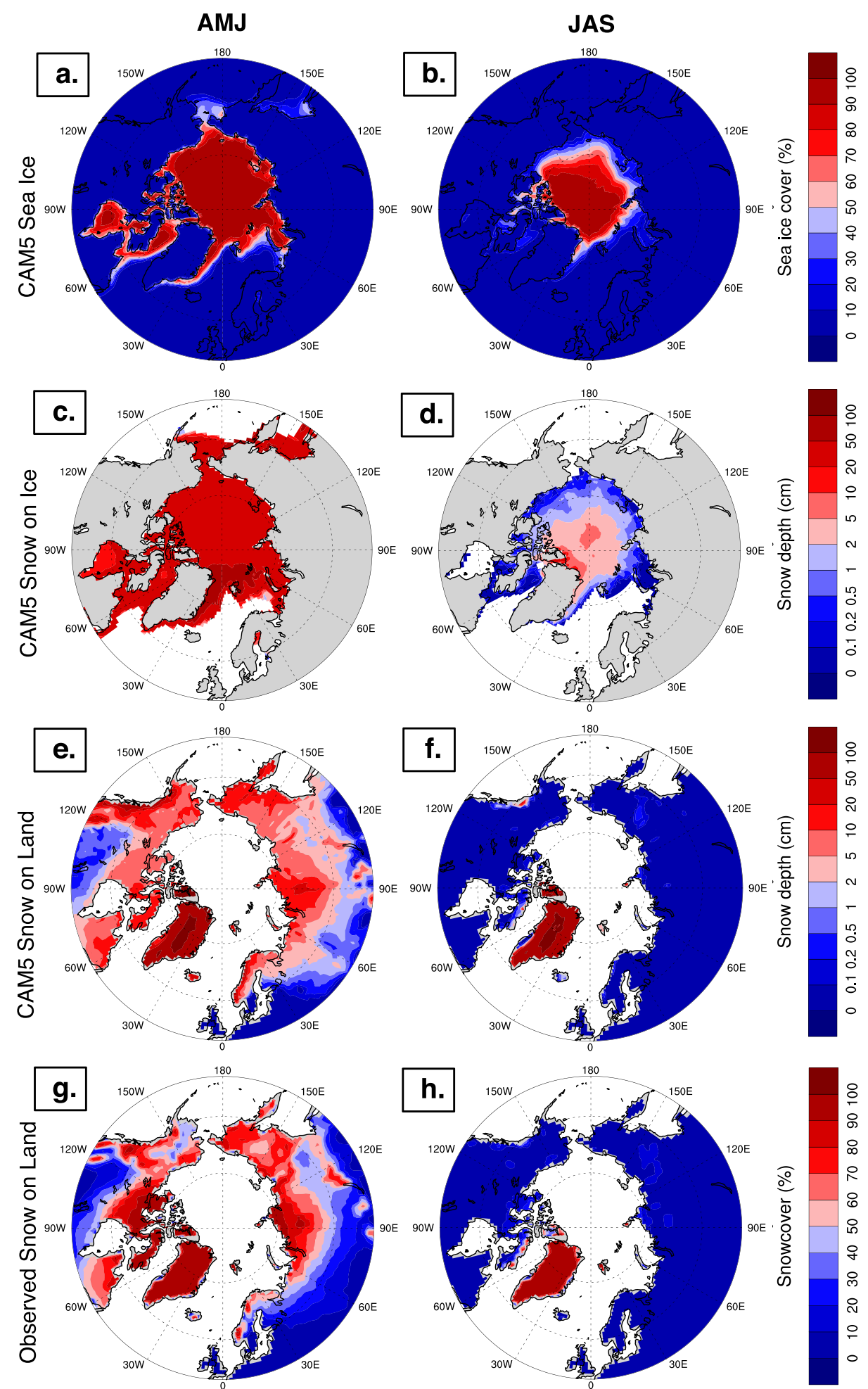

FIG. 7. AMJ and JAS polar spatial plots of CAM5 (a),(b) sea ice cover (\%); (c),(d) snow depth on sea ice $(\mathrm{cm})$; (e),(f) snow depth on land $(\mathrm{cm})$; and $(\mathrm{g}),(\mathrm{h})$ National Oceanic and Atmospheric Administration (NOAA) and Rutgers observed snow-cover extent (\%) across 11 yr (2000-10). Sea ice and SST were prescribed in the model simulations. 
areas such as southern Alaska (Figs. 6c,d). These biases correspond to mountainous regions that retain snow cover during the spring and summer months. A comparison of CAM5 snow depth (Figs. 7e,f) to observed snow-cover extent (Figs. 7g,h) averaged over the same time period (2000-10) suggests CAM5 has excessive snow in some places, explaining some of the SW clear-sky biases. However, the regions with the largest SW clear-sky biases have consistently high snow-cover extent in the model as well as observations. This suggests possible biases with the CAM5 land model treatment of snow albedo or fractional snow cover.

Finally, there appears to be other SW clear-sky differences between CAM5 and CERES-EBAF, including a discontinuity in biases around $60^{\circ} \mathrm{N}$ over both land and ocean. Some of these biases may be due to errors in the CERES-EBAF clear-sky algorithm, which are discussed in more detail in section 6 .

\section{b. Arctic OLR flux biases}

The seasonal cycle of CAM5 and CESM1 OLR biases across the Arctic basin $\left(60^{\circ}-82^{\circ} \mathrm{N}\right)$ are compared to CERES-EBAF (Fig. 8). CAM5 and CESM1 have smaller than observed OLR all-sky, clear-sky, and cloud forcing year-round over basin, land, and water. (A negative OLR bias means the model predicts insufficient OLR leaving the Arctic system.) The winter OLR clear-sky bias is partially a result of CAM5 surface temperatures being too cold; prior work has found insufficient CAM5 winter cloud amount and LWP, which allows too much radiative cooling (Liu et al. 2011; Morrison et al. 2012; Xie et al. 2013). The summer OLR clear-sky bias is partially a result of excessive atmospheric water vapor; when compared to a 10-yr average of ARM NSA observations at Barrow (2000-10), specific humidity is about $20 \%$ higher in CAM5 in the summer months (not shown), but it is not clear if this can be extrapolated to the entire Arctic basin. If so, it is possible that the model transports too much moisture from lower latitudes. CAM5 OLR cloud forcing is also too low throughout most of the year, except spring, meaning that OLR forced by CAM5 clouds is too low. This is attributed to excessive Arctic clouds in CAM5 between 6 and $12 \mathrm{~km}$, which was noted previously (Fig. 3c). Excess high altitude clouds, with their cold cloud tops, reduce OLR.

\section{c. Arctic net TOA radiative flux biases $(S W+L W)$}

On average, net TOA SW all-sky biases in CAM5 are positive (too much energy in the Arctic system) and OLR biases are negative (also too much energy in the Arctic system), resulting in a positive net TOA $\mathrm{SW}+$ OLR bias that is approximately $10 \mathrm{~W} \mathrm{~m}^{-2}$ yearround (Fig. 9a). Insufficient cloud amount, excess snow cover, and snow albedo errors contribute to SW biases, while cold winter surface temperatures (because of excess radiative cooling from insufficient low cloud amount and LWP), excessive atmospheric water vapor in summer, and excessive middle and high cloud amount year-round contribute to OLR biases.

\section{Results: Modified mixed-phase ice nucleation schemes}

We next assess the impacts of two new mixed-phase ice nucleation schemes, CAM5 Prenni and CAM5 Hoose, on CAM5 Arctic basinwide net TOA radiative fluxes, clouds, and climate. While the mixed-phase schemes were implemented globally in the model, the climate impacts of these modified schemes are most significant at high latitudes, where mixed-phase regimes (supersaturated temperatures between $0^{\circ}$ and $-37^{\circ} \mathrm{C}$ ) are most common. This high-latitude impact was also noted in other studies of mixed-phase ice nucleation schemes (Xie et al. 2013). Hence, we present analyses of their impacts in the Arctic region.

\section{a. Ice nuclei and surface climate}

The seasonal cycles of number of ice nuclei, cloud LWP, downwelling longwave radiation, and surface temperature for simulations with three different mixedphase ice nucleation schemes are plotted in the Arctic (Fig. 10). While the CAM5 Prenni and CAM5 Hoose schemes predict about an order of magnitude lower number of ice crystal nuclei from mixed-phase ice nucleation than CAM5 Meyers, the total number of ice nuclei between 300 and $1000 \mathrm{hPa}$ is reduced by about a factor of 3 year-round because of the contributions of other processes and sources and sinks. The decrease in ice number slows the WBF process, which in turn increases cloud LWP, particularly in the colder months, where LWP is low in the reference model and mixedphase cloud temperatures are common (Fig. 10a). LWP approximately doubles in winter for both CAM5 Prenni and CAM5 Hoose schemes compared to CAM5 Meyers, increasing downwelling $\mathrm{LW}$ radiation by about $10 \mathrm{~W} \mathrm{~m}^{-2}$ and increasing surface temperature by about $2^{\circ} \mathrm{C}$ (Fig. 10b). The changes to ice number, LWP, downwelling longwave radiation, and winter surface temperature improve CAM5 comparisons to M-PACE observations, as has been previously documented when implementing other 

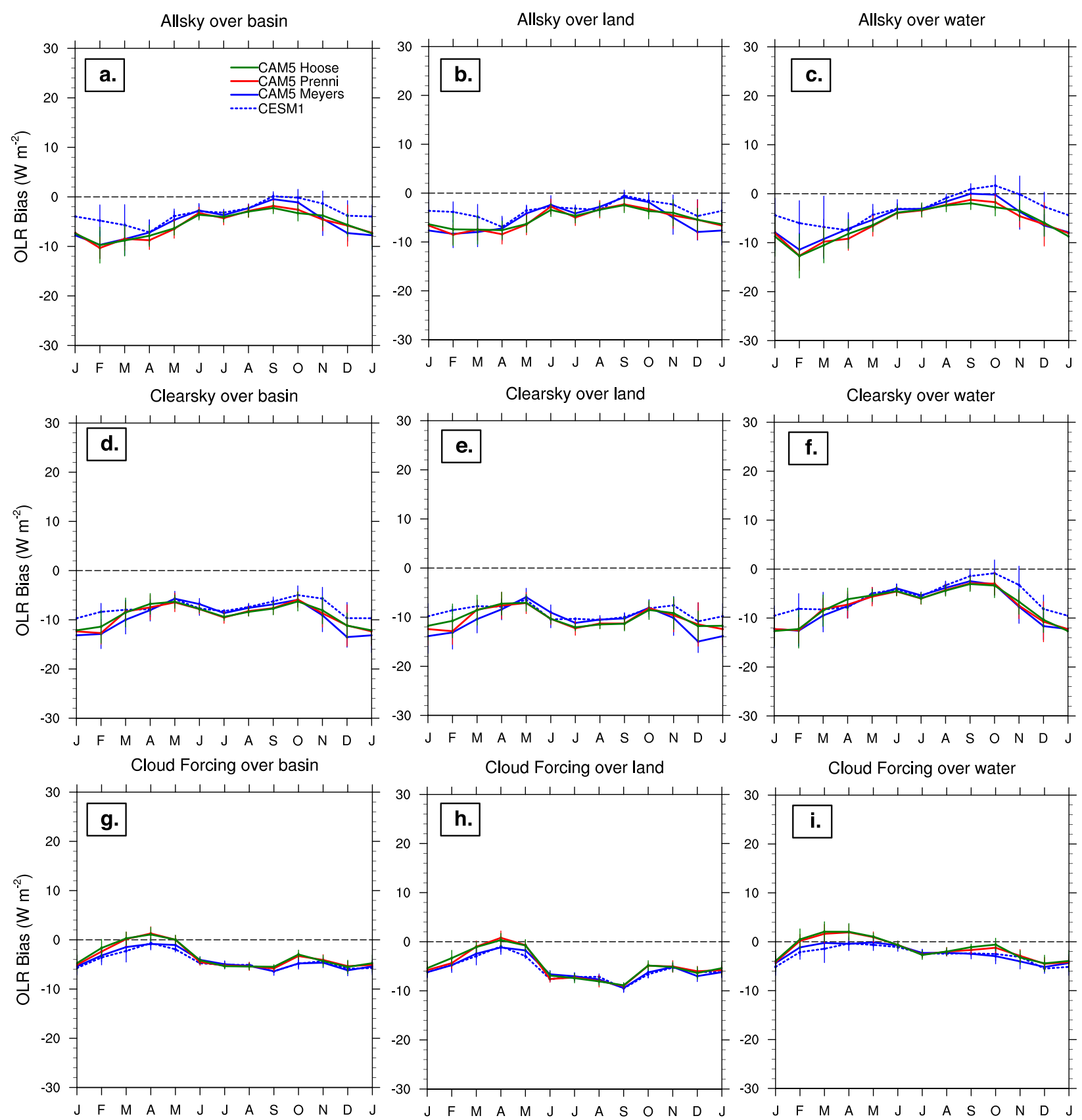

FIG. 8. As in Fig. 5, but for OLR biases. A negative OLR bias means the model predicts insufficient OLR leaving the Arctic system.

improved mixed-phase ice nucleation schemes in CAM5 (Liu et al. 2011; Xie et al. 2008). Across the Arctic basin, the CAM5 Hoose scheme predicts $15 \%$ fewer ice nuclei than CAM5 Prenni annually averaged from 300 to $1000 \mathrm{hPa}$. However, the known CAM5 aerosol low biases in the Arctic (Wang et al. 2013) likely propagate to biases in the prediction of ice nuclei as well as cloud condensation nuclei. Given the significant differences in how they predict ice nuclei, it is surprising that CAM5 Prenni and
CAM5 Hoose schemes predict such similar results, providing reassurance that the physically based scheme (CAM5 Hoose) is able to predict ice number similar to the one derived from observations (CAM5 Prenni).

\section{b. Clouds, TOA radiative fluxes, and surface weather states}

The seasonal cycle of cloud amount using the new CAM5 lidar simulator with a correction for an error in 

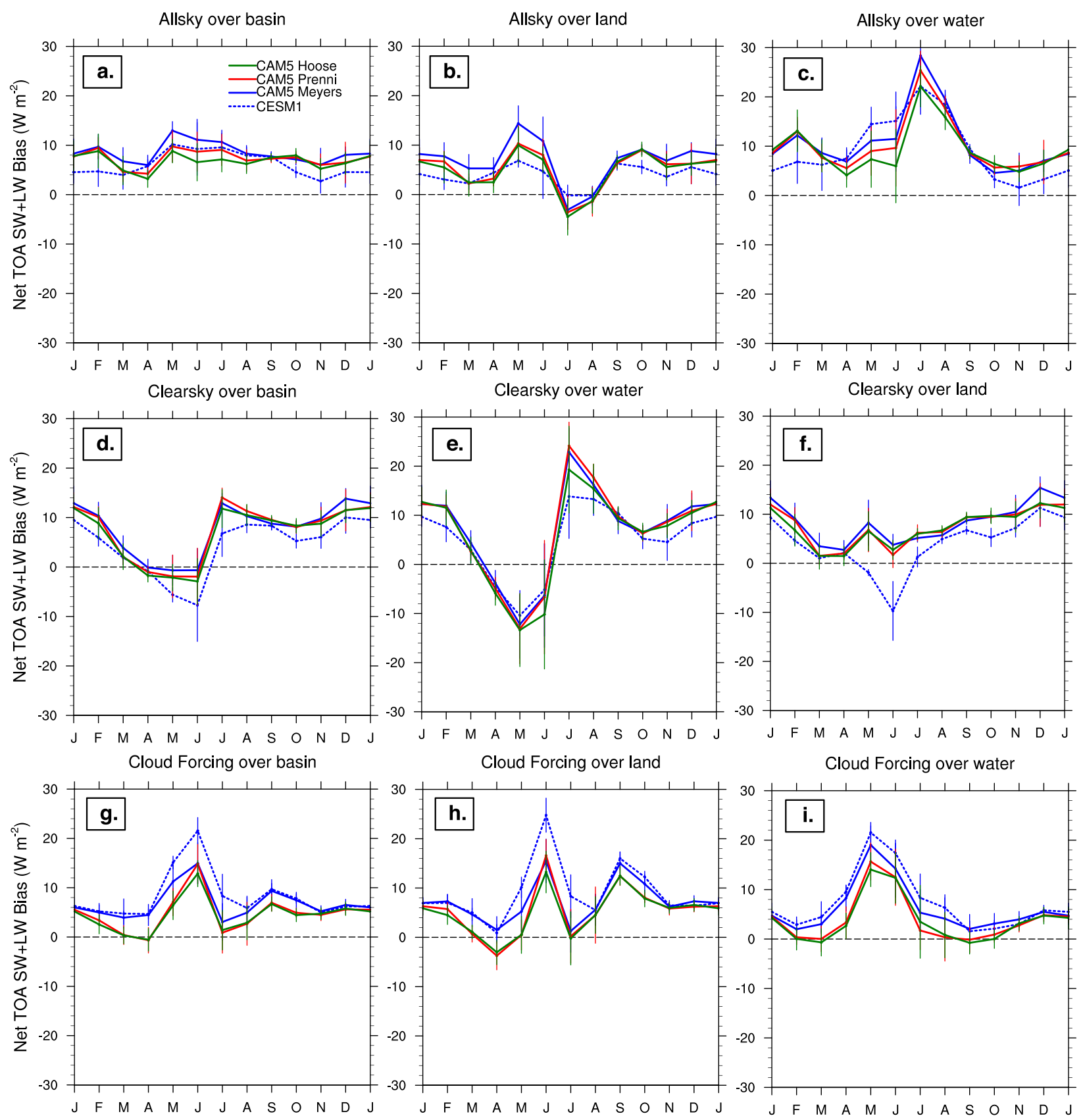

FIG. 9. As in Fig. 5, but for the CAM5 net TOA bias, calculated as net TOA SW bias minus OLR bias for consistent sign convention. A positive net bias means the model predicts excess energy entering the Arctic system.

the treatment of snow crystal size is compared for the three simulations and CALIPSO-GOCCP (Fig. 11). The CAM5 Prenni and CAM5 Hoose schemes predict an increase in CALIPSO total cloud amount in the Arctic (Fig. 11a), particularly in the winter months, where they compare favorably to CALIPSO-GOCCP. Much of the increase in winter months is due to an increase in low cloud (Fig. 11d), which is predominantly mixed-phase clouds, although in CAM5 Meyers these clouds are mainly ice clouds because of very low LWP. Most of the increase in cloud amount for the CAM5 Hoose and CAM5 Prenni simulations is over the Arctic Ocean, Siberia, and northern Canada, leading to significantly improved comparisons to CALIPSO-GOCCP (Fig. 12). The native model output of cloud amount (Fig. 11, dotted lines) is significantly higher than CAM5 CALIPSO cloud amount; in winter, for example, native cloud amount is almost twice that of CAM5 CALIPSO cloud amount. 

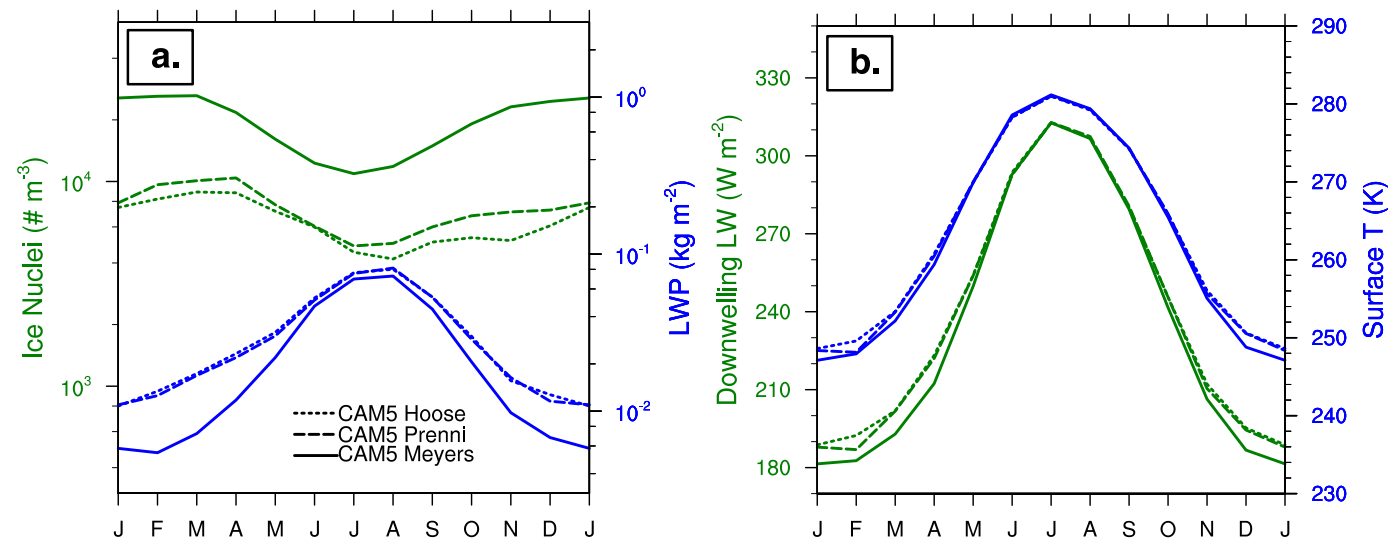

FIG. 10. Seasonal cycle of simulated monthly average (a) ice nuclei concentration $\left(\mathrm{m}^{-3}\right)$ and $\mathrm{LWP}\left(\mathrm{kg} \mathrm{m}^{-2}\right)$, and (b) downwelling longwave radiation $\left(\mathrm{W} \mathrm{m}^{-2}\right)$ and surface temperature $(\mathrm{K})$ for the three simulations in the Arctic $\left(60^{\circ}-82^{\circ} \mathrm{N}\right)$. Ice nuclei concentration is calculated by averaging the sum of all vertical levels between 100 and $1000 \mathrm{hPa}$.

As we noted in section $3 b$, most of these clouds are too optically thin to be observed by CALIPSO (equivalent to a cirrus cloud with an optical depth of less than 0.1). Hence, they also have a minor contribution to radiative fluxes as well, supporting our argument that it is best to analyze CAM5 CALIPSO cloud amount rather than native model output when investigating radiative impacts of clouds. The native model output is comparable for all three simulations, suggesting that it is not cloud frequency that is increasing; rather, an increase in optical thickness of native model clouds is enabling a higher fraction of them to be detected by CALIPSOGOCCP. One case where the three schemes deviate is that native model output of low cloud amount in CAM5 Meyers is higher, yet its cloud amount using the CALIPSO lidar simulator is lower in winter than CAM5 Prenni and CAM5 Hoose (Fig. 11d). It is possible that, because of a lack of cloud liquid production in clouds, CAM5 Meyers clouds are thinner but occur more often because of a slower depletion of water vapor.

Despite increases to cloud amount, cloud LWP, downwelling longwave radiation, and winter surface temperature, CAM5 Prenni and CAM5 Hoose schemes do not improve net TOA SW radiative flux biases compared to CAM5 Meyers (Fig. 5). Monthly average all-sky SW biases in late spring and summer are improved by about $5 \mathrm{~W} \mathrm{~m}^{-2}$, but the differences are within the error bars (one standard deviation). Additionally, approximately half of the improvement for CAM5 Prenni and CAM5 Hoose is due to a more negative SW clear-sky bias in early summer versus CERES-EBAF (Fig. 5d) compensating for the positive cloud-forcing bias. This more negative clear-sky bias is attributed to higher snow cover in CAM5 Prenni and CAM5 Hoose than CAM5 Meyers. The other half of the improvement in SW all-sky biases is due to a reduction in cloud-forcing biases, which can be attributed to increased cloud amount and LWP, which increases optical depth. Likewise, OLR biases (Fig. 8) are comparable for all three schemes. Why are TOA radiative flux biases not improved, despite improvements to cloud amount, cloud LWP, downwelling longwave radiation, and winter surface temperature? Comparisons of vertical profiles of cloud amount, temperature, and specific humidity provide some insight (Fig. 13). All three simulations have excessive cloud amount between 5 and $12 \mathrm{~km}$. In addition, the CAM5 Prenni and CAM5 Hoose schemes also have excessive cloud amount from 2 to $5 \mathrm{~km}$ (Figs. 13c,d, respectively), where temperatures are commonly mixed phase (from $0^{\circ}$ to $-35^{\circ} \mathrm{C}$ ). While the surface is warmer in the CAM5 Prenni and CAM5 Hoose simulations than CAM5 Meyers, in the region at $2-5 \mathrm{~km}$ temperatures are generally about $1^{\circ} \mathrm{C}$ cooler (Figs. 13e,f) and specific humidity is higher (Figs. 13g,h).

Finally, we explore impacts of the mixed-phase ice nucleation schemes on Arctic weather states as defined by the frequency distribution of instantaneous net surface longwave radiation. Morrison et al. (2012) noted a bimodal distribution of weather states during SHEBA, with a peak near $0 \mathrm{~W} \mathrm{~m}^{-2}$ (thick low clouds) and another peak at roughly $-40 \mathrm{~W} \mathrm{~m}^{-2}$ (clear skies). Neither CAM5 nor the Laboratoire de Météorologie Dynamique-Zoom general circulation model (LMDZ5B) were able to reproduce peak in the cloudy state at $0 \mathrm{~W} \mathrm{~m}^{-2}$ (Cesana et al. 2012). Following Cesana et al. (2012), Fig. 14 shows the probability distribution of net surface longwave radiation for SHEBA and the CAM5 simulations. While CAM5 Prenni and CAM5 Hoose slightly improve the probability distributions compared to CAM5 Meyers, none of simulations reproduces the observed peak near $0 \mathrm{~W} \mathrm{~m}^{-2}$ in any season. 
Total cloud over basin

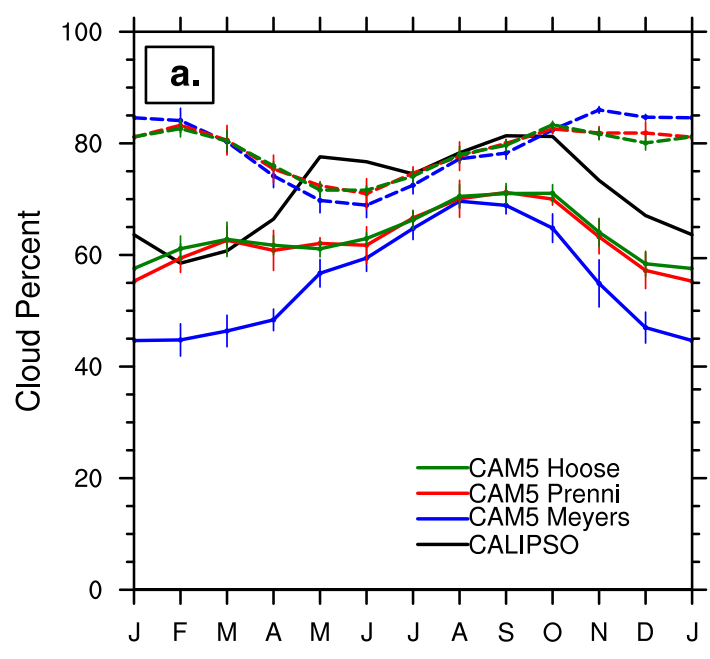

Mid cloud over basin

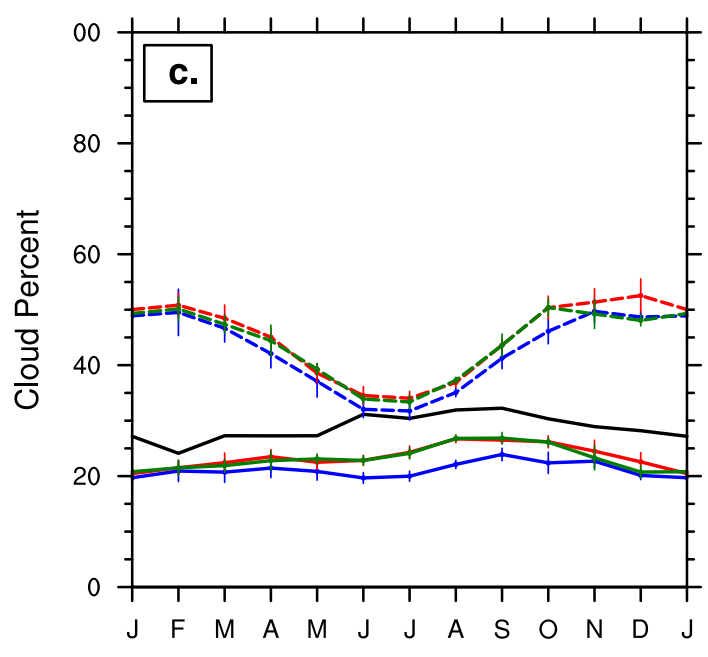

High cloud over basin

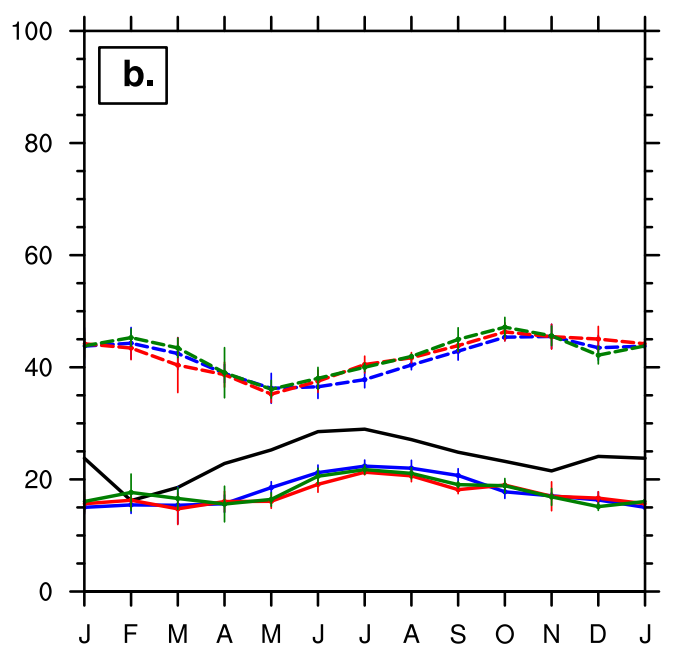

Low cloud over basin

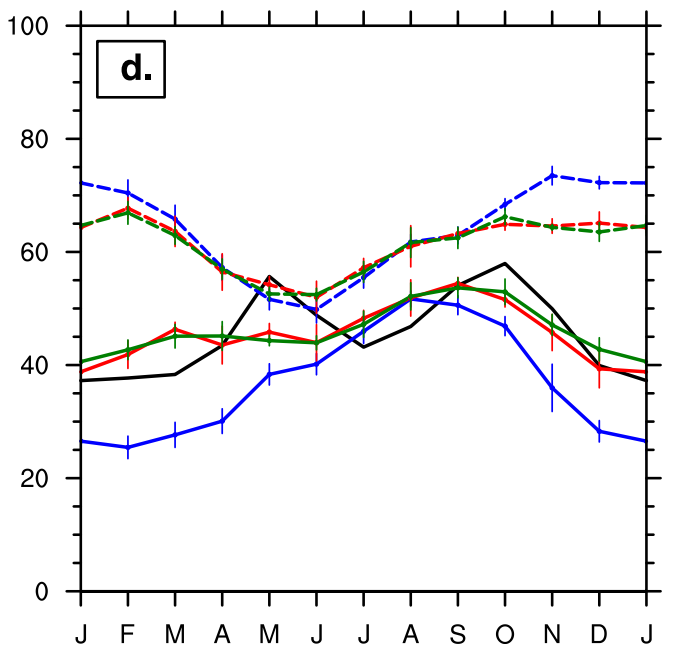

FIG. 11. Seasonal cycle of monthly average (a) total, (b) high, (c) middle, and (d) low cloud amount (\%) from $60^{\circ}$ to $82^{\circ} \mathrm{N}$ for 5-yr average (2006-10) of CALIPSO-GOCCP observations (black lines) and CAM5 simulations (colored lines). Solid lines are for the new lidar simulator; dashed lines are native model output.

\section{Discussion and conclusions}

CAM5 Arctic net TOA radiative fluxes are generally within $10 \mathrm{~W} \mathrm{~m}^{-2}$ of CERES-EBAF. However, CAM5 SW clear-sky fluxes are generally too low, while SW cloud-forcing fluxes are generally too high, meaning that the model has compensating biases in TOA radiative fluxes. CAM5's excessive SW cloud forcing (meaning too much SW enters the Arctic system) is attributed to smaller cloud amount and LWP in the model. Comparisons of CAM5 cloud amount to CALIPSO-GOCCP using a new lidar simulator with a correction for an error in the treatment of snow crystal size reinforce this conclusion; CAM5 has insufficient total, high, middle, and low cloud amount. Cloud amount using the new lidar simulator is substantially different from the CAM5 CMIP5 lidar version, suggesting the importance of radiatively activate snow on cloud amount and the impacts that lidar code can have on predicted cloud amount.

CAM5's insufficient SW clear-sky fluxes are largely a result of snow albedo being too high over sea ice and some land areas. The albedo biases over sea ice may be related to lack of aerosol deposition onto snow, excessive snow depth, errors with wet snow parameterization, and/or errors in melt pond parameterization. The albedo biases over land are likely due to both excess snow cover in the model and snow albedo errors. While the land model component of CAM5 contains a sophisticated snow component (see section 2), there may be errors with subgrid (fractional) snow cover, which is parameterized 

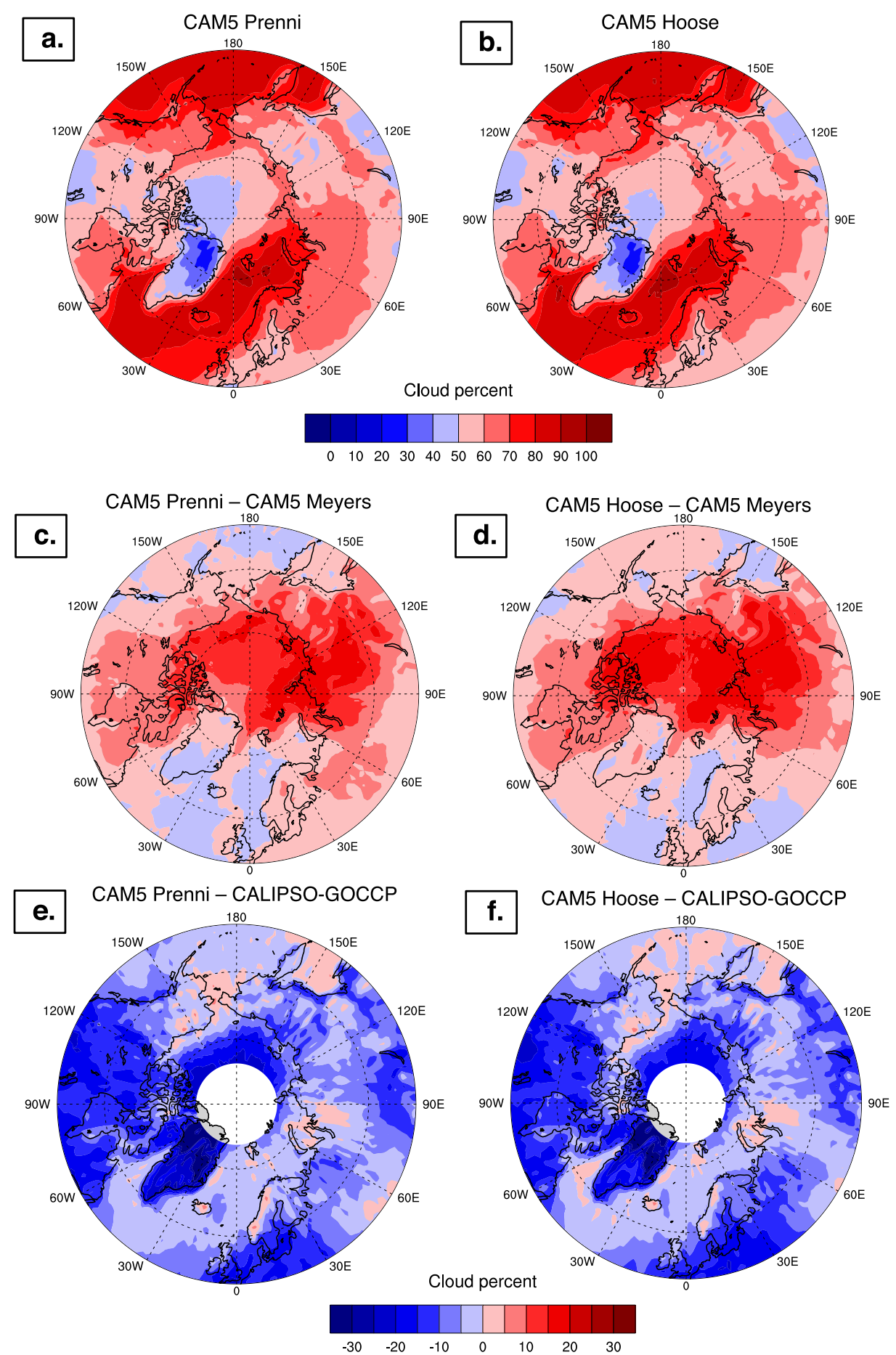

FIG. 12. Annual average polar spatial plots of cloud amount with the new lidar simulator across a 5-yr time period (2006-10) of (a) CAM5 Prenni, (b) CAM5 Hoose, (c) CAM5 Prenni - CAM5 Meyers, (d) CAM5 Hoose - CAM5 Meyers, (e) CAM5 Prenni - CALIPSO-GOCCP, and (f) CAM5 Hoose - CALIPSO-GOCCP. 

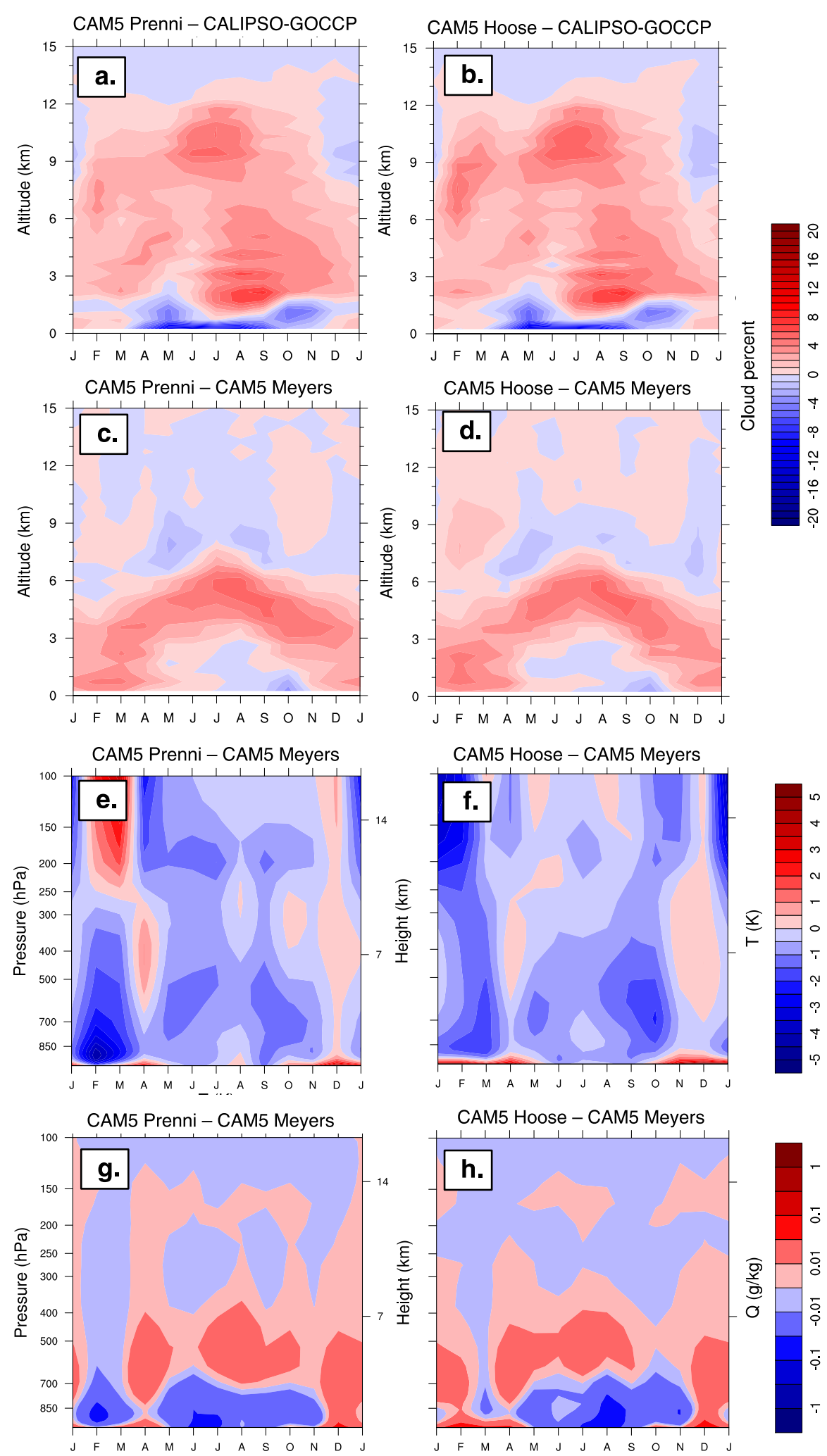

FIG. 13. Vertical contour difference plots of seasonal cycle of monthly averages of (a)-(d) cloud amount (\%); (e),(f) temperature (K); and (g),(h) specific humidity $\left(\mathrm{g} \mathrm{kg}^{-1}\right)$ from $60^{\circ}$ to $82^{\circ} \mathrm{N}$ across $5 \mathrm{yr}(2006-10)$. Modeled cloud amount uses the new CAM5 lidar simulator with a correction for an error in the treatment of snow crystal size. 

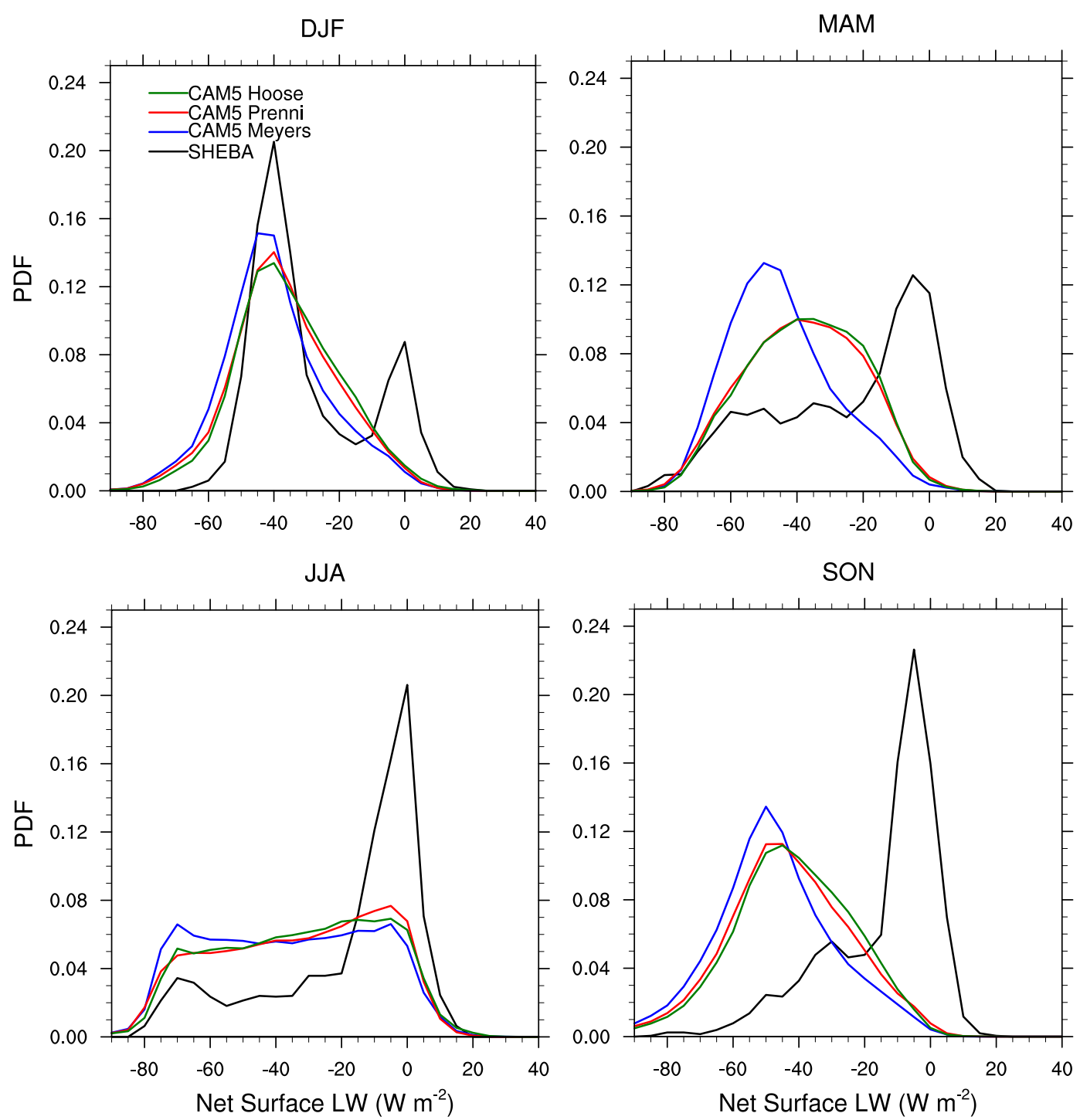

FIG. 14. Probability distributions of net surface longwave radiation $\left(\mathrm{W} \mathrm{m}^{-2}\right)$ for four seasons across the Beaufort Sea $\left(70^{\circ}-80^{\circ} \mathrm{N}, 170^{\circ}-120^{\circ} \mathrm{W}\right)$ for SHEBA observations (black lines) and CAM5 model simulations (colored lines). SHEBA data are derived from 1-h averages from October 1997 to October 1998, while CAM5 output utilizes 5 yr (2000-05) of 27-h instantaneous output.

based only upon snow depth in CAM5 and likely does not accurately represent the actual snow-cover surface area present in mountainous regions in summer, such as in southern Alaska. Aged snow in CAM5 may also have insufficient aerosol deposition; indeed other work has found insufficient aerosol at high latitudes (Wang et al. 2013). New observations would be helpful to constrain some of these parameters.

Some of the SW clear-sky differences between CAM5 and CERES-EBAF (Fig. 6) may be attributed to errors and uncertainties with CERES-EBAF retrievals. For example, CAM5 has excessive SW clear sky over water in the Arctic Ocean between Greenland and Scandinavia in
AMJ (Fig. 6c) and JAS (Fig. 6d). Since sea ice extent was prescribed in these CAM5 simulations, it is unlikely the bias is due to incorrect surface type. This region is open ocean in the model and observations. While it is possible there is a bias with the prescribed open ocean albedo in the model, it is more likely there are errors with CERESEBAF retrievals of clear-sky fluxes in this region. By definition, a near-zero all-sky SW bias coupled with a positive SW clear-sky bias means a negative SW cloudforcing bias. However, CAM5 cloud amount compares favorably to CALIPSO-GOCCP in this region between Greenland and Scandinavia (Fig. 2), which supports the suggestion that CERES-EBAF clear-sky retrieval errors 
are responsible for the difference. Note that the SW clearsky bias present between Greenland and Scandinavia is smaller than in other regions with open ocean, particularly at latitudes south of $60^{\circ} \mathrm{N}$. There appears to be a discontinuity in SW clear-sky biases at $60^{\circ} \mathrm{N}$ over both land and ocean. This too suggests clear-sky retrieval issues with CERES-EBAF. There is much difficulty obtaining accurate high-latitude retrievals of clear-sky radiative fluxes because of low-albedo contrasts between clouds and snow combined with high-latitude zenith angles. CERES-EBAF version 2.7 employs two different algorithms to determine clear-sky fluxes depending on the solar zenith angle. If solar zenith angles are less than $82^{\circ}$, clear-sky irradiances are derived from snow/ice angular distribution models if snow/ice is present in a CERES footprint and no clouds are detected (Kato and Loeb 2005). If footprints are partly cloudy, narrowband to broadband conversions of MODIS radiances are utilized (Loeb et al. 2009). However, at solar zenith angles greater than $82^{\circ}$, the daytime algorithm with MODIS cannot be utilized and a nighttime algorithm is implemented (Minnis et al. 2011). There can be discontinuities between the two algorithms, and this appears to be the case at around $60^{\circ} \mathrm{N}$. The discontinuity near $60^{\circ} \mathrm{N}$ is not universally present at all longitudes, suggesting that the two algorithms are sometimes in agreement. Likewise, it is possible that both algorithms sometimes have errors. There are also SW clear-sky differences between different versions of CERES-EBAF. Version 2.7, which improves partly cloudy algorithms compared to version 2.6 , differs spatially by up to $20 \mathrm{~W} \mathrm{~m}^{-2}$ seasonally (not shown). In CERES-EBAF version 2.7, the gradient at $60^{\circ} \mathrm{N}$ is reduced compared to version 2.6, suggesting more consistency as a function of latitude. However, CAM5 SW clear-sky TOA biases over the polar ice cap are higher when compared to version 2.7. In AMJ, CAM5 clear-sky TOA SW biases over the polar ice cap are about $30 \mathrm{~W} \mathrm{~m}^{-2}$ too low compared to version 2.7 and about $20 \mathrm{~W} \mathrm{~m}^{-2}$ too low compared to version 2.6. In JAS, CAM5 SW clear-sky biases over the polar ice cap are about $15 \mathrm{~W} \mathrm{~m}^{-2}$ too high compared to version 2.7 and near zero compared to version 2.6. Differences in OLR clear sky between the two versions of CERES-EBAF were smaller than the differences in net TOA SW clear sky. Nonetheless, much of our analysis of CAM5 clearsky biases is supported by alternate comparisons, suggesting model biases rather than CERES-EBAF retrieval errors. For example, CAM5's excessive SW cloud forcing versus CERES-EBAF is consistent with CAM5's insufficient cloud amount versus CALIPSO. Likewise, CAM5's SW clear-sky biases over mountainous snowcovered regions correspond to places with snow cover in the model. These biases are present also when comparing to CERES-EBAF all-sky fluxes, which are not subjected to the cloud-clearing algorithm errors associated with clear-sky fluxes. In these regions CAM5 cloud amount compares favorably to CALIPSO in AMJ and JAS (not shown), suggesting that clear-sky biases, not cloudforcing biases, are contributing to the all-sky biases.

CAM5 OLR all-sky, clear-sky, and cloud-forcing fluxes are too low year-round. In winter, the OLR bias is partially attributed to cold surface temperatures due excessive radiative cooling from insufficient mixedphase clouds, which has been reported previously (Liu et al. 2011; Xie et al. 2013). In summer, excess atmospheric water vapor (specific humidity) may contribute to OLR biases, which may be due to excessive transport of moisture from lower latitudes. Year-round OLR biases may be related to excess cloud amount in the middle and upper troposphere. Comparisons of CAM5 cloud amount to CALIPSO-GOCCP using a new lidar simulator with a correction for an error in the treatment of snow crystal size reveal that CAM5 has excess cloud amount in the middle and upper troposphere based on vertical contour plots. However, comparisons of middle and high cloud amount to CALIPSO-GOCCP using the new CAM5 lidar simulator suggest that CAM5 has insufficient cloud amount. This perceived discrepancy is due to CAM5 cloud frequency being too low, yet the vertical extent of CAM5 clouds that do occur is too high, particularly between 3 and $12 \mathrm{~km}$. It is unclear why CAM5 has excessive clouds. At these altitudes, the clouds are mostly ice. Instantaneous model output reveals these clouds often extend from the surface up to 9-12 km, suggesting they are produced from the convection scheme. It is possible that the model ice nucleation parameterization is too sensitive to subgrid-scale uplift in this region. A study of Arctic weather states found that excessive middle and high cloud amount in CAM5 occurred most often during the weak uplift regime (Barton et al. 2012). With the new lidar simulator, the CAM5 bias during the weak uplift regime was reduced but excess cloud amount still occurred above $4 \mathrm{~km}$ (N. Barton 2013, personal communication), suggesting possible errors with model parameterization of uplift. It is also possible that the model's vertical resolution of about $1 \mathrm{~km}$ per level in the middle and upper troposphere contributes to the bias; as in CAM5, a cloud always fills the entire height of the grid box. Model horizontal grid resolution appears to contribute to this bias, as running at $2^{\circ}$ resolution increased the high cloud bias further compared to $1^{\circ}$ resolution.

Implementing new mixed-phase ice nucleation schemes increased low cloud amount and LWP as expected but did not significantly impact net TOA SW or OLR biases compared to CERES-EBAF and did not significantly 
improve the probability distribution of net surface longwave fluxes compared to SHEBA. While improved, cloud amount and LWP are still low for the CAM5 Prenni and CAM5 Hoose simulations compared to CALIPSOGOCCP cloud amount across the Arctic basin and LWP at the ARM NSA site in Barrow. Recent work suggests other aerosols can contribute to heterogeneous ice nucleation (Yun and Penner 2013), and the possible role of scavenging on Arctic aerosol concentration and underestimation on LWP (Wang et al. 2013). The CAM5 Prenni and CAM5 Hoose simulations also have excessive cloud amount from 2 to $5 \mathrm{~km}$, in addition to the excessive cloud amount between 5 and $12 \mathrm{~km}$ for all three simulations. Likewise, CAM5 Prenni and CAM5 Hoose simulations have higher specific humidity and lower temperature from 2 to $5 \mathrm{~km}$ than CAM5 Meyers, increasing an already high bias in specific humidity in the Arctic. Results from an intercomparison of six cloud-resolving models suggest complex interplay between microphysics, radiation, and dynamics (Morrison et al. 2011). It is possible that errors with grid-scale or subgrid-scale microphysics such as the WBF process, instantaneous rain freezing temperature, diagnostic precipitation, microphysics/macrophysics coupling, or cloud microphysics substepping frequency may contribute to the biases. For example, CAM5 assumes that liquid and ice layers within a cloud are well mixed, yet observations suggest that the cloud top is mostly liquid with ice precipitating downward (Shupe et al. 2008). The WBF process is dependent upon local relative concentrations of liquid and ice nuclei, and the lack of subgrid cloud variability in the model may unrealistically increase conversion of cloud liquid to cloud ice.

Overall, results suggest improvements to surface climate using the CAM5 Prenni and CAM5 Hoose mixedphase ice nucleation schemes. The CAM5 Hoose scheme is particularly useful as it provides a more physically realistic representation of mixed-phase cloud nucleation processes. Our results suggest that CAM5 Arctic climate could still be improved with model improvements that increase cloud amount and LWP while decreasing atmospheric water vapor, snow cover, and snow albedo. Model improvements to accomplish this may include improvements to precipitation processes, microphysics/macrophysics coupling, subgrid-scale processes including the WBF process, and changes to transport of moist static energy from lower latitudes. The next version of CAM5 cloud microphysics will include many new and improved processes including several of those recommended here.

Acknowledgments. Support for J. M. English was provided by NASA Award NNX09AJ05G. Support for X. Liu was provided by the DOE Office of Science Atmospheric
System Research (ASR) Program and Earth System Modeling Program. Support for Y. Zhang was provided by the Earth System Modeling program of the U.S. Department of Energy. Thanks to NOAA and Rutgers for snow-cover data and to Mark Flanner for providing them in a convenient format. Thanks to Gijs de Boer for providing SHEBA data in a convenient format, to David Bailey for insightful conversations regarding the sea ice model, to Dave Lawrence for insightful conversations regarding the land model, and to Neil Barton for providing new cloud plots using the new lidar code. Thanks to NASA and CNES for CALIOP and CERES data. The Pacific Northwest National Laboratory (PNNL) is operated for the DOE by Battelle Memorial Institute under Contract DE-AC06-76RLO 1830. Work at LLNL was performed under the auspices of the U.S. Department of Energy by LLNL under Contract DEAC52-07NA27344.

\section{REFERENCES}

Barton, N. P., S. A. Klein, J. S. Boyle, and Y. Y. Zhang, 2012: Arctic synoptic regimes: Comparing domain-wide Arctic cloud observations with CAM4 and CAM5 during similar dynamics. J. Geophys. Res., 117, D15205, doi:10.1029/2012JD017589.

Bergeron, T., 1935: On the physics of clouds and precipitation. Proces Verbaux de l'Association de Meteorologie, International Union of Geodesy and Geophysics, 156-178.

Bigg, E. K., 1953: The supercooling of water. Proc. Phys. Soc., 66, 688-694, doi:10.1088/0370-1301/66/8/309.

, 1996: Ice forming nuclei in the high Arctic. Tellus, 48B, 223 233, doi:10.1034/j.1600-0889.1996.t01-1-00007.x.

Bodas-Salcedo, A., and Coauthors, 2011: COSP: Satellite simulation software for model assessment. Bull. Amer. Meteor. Soc., 92, 1023-1043, doi:10.1175/2011BAMS2856.1.

Bony, S., M. Webb, C. Bretherton, S. A. Klein, P. Siebesma, G. Tselioudis, and M. Zhang, 2011: CFMIP: Towards a better evaluation and understanding of clouds and cloud feedbacks in CMIP5 models. CLIVAR Exchanges, No. 56, International CLIVAR Project Office, Southampton, United Kingdom, 20-24.

Bretherton, C. S., and S. Park, 2009: A new moist turbulence parameterization in the Community Atmosphere Model. J. Climate, 22, 3422-3448, doi:10.1175/2008JCLI2556.1.

Cesana, G., and H. Chepfer, 2012: How well do climate models simulate cloud vertical structure? A comparison between CALIPSO-GOCCP satellite observations and CMIP5 models. Geophys. Res. Lett., 39, L20803, doi:10.1029/ 2012GL053153.

- J. E. Kay, H. Chepfer, J. M. English, and G. de Boer, 2012: Ubiquitous low-level liquid-containing Arctic clouds: New observations and climate model constraints from CALIPSOGOCCP. Geophys. Res. Lett., 39, L20804, doi:10.1029/ 2012GL053385.

Chepfer, H., M. Chiriaco, R. Vautard, and J. Spinhirne, 2007: Evaluation of MM5 optically thin clouds over Europe in fall using ICE/SAT lidar space-born observations. Mon. Wea. Rev., 135, 2737-2753, doi:10.1175/MWR3413.1.

S. Bony, D. M. Winker, M. Chiriaco, J.-L. Dufresne, and G. Seze, 2008: Use of CALIPSO lidar observations to evaluate 
the cloudiness simulated by a climate model. Geophys. Res. Lett., 35, L15704, doi:10.1029/2008GL034207.

—_ — — — - G. Cesana, J. L. Dufresne, P. Minnis, C. J. Stubenrauch, and S. Zeng, 2010: The GCM Oriented CALIPSO Cloud Product (CALIPSO-GOCCP). J. Geophys. Res., 115, D00H16, doi:10.1029/2009JD012251.

- , G. Cesana, D. Winker, B. Getzewich, M. Vaughan, and Z. Liu, 2013: Comparison of two different cloud climatologies derived from CALIOP-attenuated backscattered measurements (level 1): The CALIPSO-ST and the CALIPSOGOCCP. J. Atmos. Oceanic Technol., 30, 725-724, doi:10.1175/ JTECH-D-12-00057.1.

Chiriaco, M., R. Vautard, H. Chepfer, M. Haeffelin, J. Dudhia, Y. Wanherdrick, Y. Morille, and A. Protat, 2006: The ability of MM5 to simulate ice clouds: Systematic comparison between simulated and measured fluxes and lidar/radar profiles at the SIRTA atmospheric observatory. Mon. Wea. Rev., 134, 897918, doi:10.1175/MWR3102.1.

de Boer, G., E. W. Eloranta, and M. D. Shupe, 2009: Arctic mixedphase stratiform cloud properties from multiple years of surface-based measurements at two high-latitude locations. J. Atmos. Sci., 66, 2874-2887, doi:10.1175/2009JAS3029.1.

- H. Morrison, M. D. Shupe, and R. Hildner, 2011: Evidence of liquid dependent ice nucleation in high-latitude stratiform clouds from surface remote sensors. Geophys. Res. Lett., 38, L01803, doi:10.1029/2010GL046016.

— Arctic Summer Cloud Ocean Study (ASCOS): Evaluation of reanalyses and global climate models. Atmos. Chem. Phys. Discuss., 13, 19 421-19470, doi:10.5194/acpd-13-19421-2013.

DeMott, P. J., and Coauthors, 2010: Predicting global atmospheric ice nuclei distributions and their impacts on climate. Proc. Natl. Acad. Sci. USA, 107, 11217-11222, doi:10.1073/ pnas.0910818107.

Dong, X., B. Xi, K. Crosby, C. N. Long, R. S. Stone, and M. D. Shupe, 2010: A 10 year climatology of Arctic cloud fraction and radiative forcing at Barrow, Alaska. J. Geophys. Res., 115, D17212, doi:10.1029/2009JD013489.

Findeisen, W., 1938: Kolloid-meteorologische Vorgänge bei Neiderschlags-bildung. Meteor. Z., 55, 121-133.

Flanner, M. G., and C. S. Zender, 2005: Snowpack radiative heating: Influence on Tibetan Plateau climate. Geophys. Res. Lett., 32, L06501, doi:10.1029/2004GL022076.

— evolution. J. Geophys. Res., 111, D12208, doi:10.1029/ 2005JD006834.

,-- J. T. Randerson, and P. J. Rasch, 2007: Present-day climate forcing and response from black carbon in snow. J. Geophys. Res., 112, D11202, doi:10.1029/2006JD008003.

Fletcher, N. H., 1962: The Physics of Rain Clouds. Cambridge University Press, 386 pp.

Gettelman, A., and Coauthors, 2010: Global simulations of ice nucleation and ice supersaturation with an improved cloud scheme in the Community Atmosphere Model. J. Geophys. Res., 115, D18216, doi:10.1029/2009JD013797.

Hollinger, J., J. Peirce, and G. Poe, 1990: SSM/I instrument evaluation. IEEE Trans. Geosci. Remote Sens., 28, 781-790, doi:10.1109/36.58964.

Hoose, C., J. E. Kristjansson, J. P. Chen, and A. Hazra, 2010: A classical-theory-based parameterization of heterogeneous ice nucleation by mineral dust, soot, and biological particles in a global climate model. J. Atmos. Sci., 67, 2483-2503, doi:10.1175/2010JAS3425.1.
Hurrell, J. W., and Coauthors, 2013: The Community Earth System Model: A framework for collaborative research. Bull. Amer. Meteor. Soc., 94, 1339-1360, doi:10.1175/BAMS-D-12-00121.1. Iacono, M. J., J. S. Delamere, E. J. Mlawer, M. W. Shephard, S. A. Clough, and W. D. Collins, 2008: Radiative forcing by longlived greenhouse gases: Calculations with the AER radiative transfer models. J. Geophys. Res., 113, D13103, doi:10.1029/ 2008JD009944.

Karlsson, J., and G. Svensson, 2013: Consequences of poor representation of Arctic sea-ice albedo and cloud-radiation interactions in the CMIP5 model ensemble. Geophys. Res. Lett., 40, 4374-4379, doi:10.1002/grl.50768.

Kato, S., and N. G. Loeb, 2005: Top-of-atmosphere shortwave broadband observed radiance and estimated irradiance over polar regions from Clouds and the Earth's Radiant Energy System (CERES) instruments on Terra. J. Geophys. Res., 110, D07202, doi:10.1029/2004JD005308.

Kay, J. E., and T. L'Ecuyer, 2013: Observational constraints on Arctic Ocean clouds and radiative fluxes during the early 21 st century. J. Geophys. Res., 118, 7219-7236, doi:10.1002/jgrd.50489.

_ , K. Raeder, A. Gettelman, and J. Anderson, 2011: The boundary layer response to recent Arctic sea ice loss and implications for high-latitude climate feedbacks. J. Climate, $\mathbf{2 4}$, 428-447, doi:10.1175/2010JCLI3651.1.

- and Coauthors, 2012: Exposing global cloud biases in the Community Atmosphere Model (CAM) using satellite observations and their corresponding instrument simulators. J. Climate, 25, 5190-5207, doi:10.1175/JCLI-D-11-00469.1.

Klein, S. A., and Coauthors, 2009: Intercomparison of model simulations of mixed-phase clouds observed during the ARM Mixed-Phase Arctic Cloud Experiment. I: Single-layer cloud. Quart. J. Roy. Meteor. Soc., 135, 979-1002, doi:10.1002/qj.416.

Lawrence, D. M., and A. G. Slater, 2010: The contribution of changes in snow conditions on future ground climate. Climate Dyn., 34, 969-981, doi:10.1007/s00382-009-0537-4.

_ , and Coauthors, 2011: Parameterization improvements and functional and structural advances in version 4 of the Community Land Model. J. Adv. Model. Earth Syst., 3, M03001, doi:10.1029/2011MS000045.

L'Ecuyer, T. S., and J. Jiang, 2010: Touring the atmosphere aboard the A-Train. Phys. Today, 63, 36-41, doi:10.1063/1.3463626.

Liu, J., M. Song, R. M. Horton, and Y. Hu, 2013: Reducing spread in climate model projections of a September ice-free Arctic. Proc. Natl. Acad. Sci. USA, 110, 12571-12576, doi:10.1073/ pnas.1219716110.

Liu, X., and Coauthors, 2011: Testing cloud microphysics parameterizations in NCAR CAM5 with ISDAC and M-PACE observations. J. Geophys. Res., 116, D00T11, doi:10.1029/ 2011JD015889.

— , and Coauthors, 2012: Toward a minimal representation of aerosols in climate models: Description and evaluation in the Community Atmosphere Model CAM5. Geosci. Model Dev., 5, 709-739, doi:10.5194/gmd-5-709-2012.

Liu, Y., S. A. Ackerman, B. C. Maddux, J. R. Key, and R. A. Frey, 2010: Errors in cloud detection over the Arctic using a satellite imager and implications for observing feedback mechanisms. J. Climate, 23, 1894-1907, doi:10.1175/2009JCLI3386.1.

Loeb, N. G., S. Kato, K. Loukachine, N. Manalo-Smith, and D. R. Doelling, 2007: Angular distribution models for top-ofatmosphere radiative flux estimation from the Clouds and the Earth's Radiant Energy System instrument on the Terra satellite. Part II: Validation. J. Atmos. Oceanic Technol., 24, 564-584, doi:10.1175/JTECH1983.1. 
_ B. A. Wielicki, D. R. Doelling, G. L. Smith, D. F. Keyes, S. Kato, N. Manalo-Smith, and T. Wong, 2009: Toward optimal closure of the Earth's top-of-atmosphere radiation budget. J. Climate, 22, 748-766, doi:10.1175/2008JCLI2637.1.

Medeiros, B., C. Deser, R. A. Tomas, and J. E. Kay, 2011: Arctic inversion strength in climate models. J. Climate, 24, 47334740, doi:10.1175/2011JCLI3968.1.

Meyers, M. P., P. J. DeMott, and W. R. Cotton, 1992: New primary ice nucleation parameterizations in an explicit cloud model. J. Appl. Meteor., 31, 708-721, doi:10.1175/1520-0450(1992)031<0708: NPINPI $>2.0 . \mathrm{CO} ; 2$

Minnis, P., and Coauthors, 2011: CERES edition-2 cloud property retrievals using TRMM VIRS and Terra and Aqua MODIS data-Part I: Algorithms. IEEE Trans. Geosci. Remote Sens. 49, 4374-4400, doi:10.1109/TGRS.2011.2144601.

Morrison, H., and J. Pinto, 2006: Intercomparison of bulk microphysics schemes in mesoscale simulations of springtime Arctic mixed-phase stratiform clouds. Mon. Wea. Rev., 134, 1880 1900, doi:10.1175/MWR3154.1.

— cloud microphysics scheme in the Community Atmosphere Model, version 3 (CAM3). Part I: Description and numerical tests. J. Climate, 21, 3642-3659, doi:10.1175/2008JCLI2105.1.

_ , and Coauthors, 2011: Intercomparison of cloud model simulations of Arctic mixed-phase boundary layer clouds observed during SHEBA/FIRE-ACE. J. Adv. Model. Earth Syst., 3, M06003, doi:10.1029/2011MS000066.

— , G. de Boer, G. Feingold, J. Harrington, M. D. Shupe, and K. Sulia, 2012: Resilience of persistent Arctic mixed-phase clouds. Nat. Geosci., 5, 11-17, doi:10.1038/ngeo1332.

Neale, R. B., and Coauthors, 2010: Description of the NCAR Community Atmosphere Model (CAM 5.0). NCAR Tech. Note NCAR/TN-486+STR, 289 pp. [Available at http://www. cesm.ucar.edu/models/cesm1.0/cam/docs/description/cam5_desc. pdf.]

Niu, G. Y., and Z. L. Yang, 2007: An observation-based formulation of snow cover fraction and its evaluation over large North American river basins. J. Geophys. Res., 112, D21101, doi:10.1029/2007JD008674.

Park, S., and C. S. Bretherton, 2009: The University of Washington shallow convection and moist turbulence schemes and their impact on climate simulations with the Community Atmosphere Model. J. Climate, 22, 3449-3469, doi:10.1175/2008JCLI2557.1.

Pithan, F., B. Medeiros, and T. Mauritsen, 2014: Mixed-phase clouds cause climate model biases in Arctic wintertime temperature inversions. Climate Dyn., doi:10.1007/s00382-013-1964-9, in press.

Prenni, A. J., and Coauthors, 2007: Can ice-nucleating aerosols effect Arctic seasonal climate? Bull. Amer. Meteor. Soc., 88, 541-550, doi:10.1175/BAMS-88-4-541.

Serreze, M. C., A. P. Barrett, J. C. Stroeve, D. N. Kindig, and M. M. Holland, 2009: The emergence of surface-based Arctic amplification. Cryosphere, 3, 11-19, doi:10.5194/tc-3-11-2009.
Shupe, M. D., P. Kollias, P. O. G. Persson, and G. M. McFarquhar, 2008: Vertical motions in Arctic mixed-phase stratus. J. Atmos. Sci., 65, 1304-1322, doi:10.1175/2007JAS2479.1.

Stramler, K., A. D. Del Genio, and W. B. Rossow, 2011: Synoptically driven Arctic winter states. J. Climate, 24, 1747-1762, doi:10.1175/2010JCLI3817.1.

Uttal, T., and Coauthors, 2002: Surface heat budget of the Arctic Ocean. Bull. Amer. Meteor. Soc., 83, 255-275, doi:10.1175/ 1520-0477(2002)083<0255:SHBOTA > 2.3.CO;2.

Verlinde, J., and Coauthors, 2007: The Mixed-Phase Arctic Cloud Experiment. Bull. Amer. Meteor. Soc., 88, 205-221, doi:10.1175/ BAMS-88-2-205.

Wang, A., and X. Zeng, 2009: Improving the treatment of the vertical snow burial fraction over short vegetation in the NCAR CLM3. Adv. Atmos. Sci., 26, 877-886, doi:10.1007/ s00376-009-8098-3.

Wang, H., and Coauthors, 2013: Sensitivity of remote aerosol distributions to representation of cloud-aerosol interactions in a global climate model. Geosci. Model Dev., 6, 765-782, doi:10.5194/gmd-6-765-2013.

Wang, Y., X. Liu, C. Hoose, and B. Wang, 2014: Impact of heterogeneous ice nucleation by natural dust and soot based on a probability density function of contact angle model with the Community Atmospheric Model version 5. Atmos. Chem. Phys. Discuss., 14, 7141-7186, doi:10.5194/acpd-14-7141-2014.

Wegener, A., 1911: Thermodynamik der Atmosphare. J. A. Barth, $331 \mathrm{pp}$.

Wielicki, B. A., B. R. Barkstrom, E. F. Harrison, R. B. Lee III, G. L. Smith, and J. E. Cooper, 1996: Clouds and the Earth's Radiant Energy System (CERES): An Earth Observing System experiment. Bull. Amer. Meteor. Soc., 77, 853-868, doi:10.1175/1520-0477(1996)077<0853:CATERE>2.0.CO;2.

Winker, D. M., M. A. Vaughan, A. Omar, Y. Hu, K. A. Powell, Z. Liu, W. H. Hunt, and S. A. Young, 2009: Overview of the CALIPSO mission and CALIOP data processing algorithms. J. Atmos. Oceanic Technol., 26, 2310-2323, doi:10.1175/ 2009JTECHA1281.1.

Xie, S., J. Boyle, S. A. Klein, X. Liu, and S. Ghan, 2008: Simulations of Arctic mixed-phase clouds in forecasts with CAM3 and AM2 for M-PACE. J. Geophys. Res., 113, D04211, doi:10.1029/ 2007JD009225.

- X. Liu, C. Zhao, and Y. Zhang, 2013: Sensitivity of CAM5simulated Arctic clouds and radiation to ice nucleation parameterization. J. Climate, 26, 5981-5999, doi:10.1175/ JCLI-D-12-00517.1.

Young, K. C., 1974: The role of contact nucleation in ice phase initiation of clouds. J. Atmos. Sci., 31, 768-776, doi:10.1175/ 1520-0469(1974)031<0768:TROCNI > 2.0.CO;2.

Yun, Y., and J. E. Penner, 2013: An evaluation of the potential radiative forcing and climatic impact of marine organic aerosols as heterogeneous ice nuclei. Geophys. Res. Lett., 40, 41214126, doi:10.1002/grl.50794. 